Effects of Heating-needle Stimulation in Restoration of Weakened Descending Inhibition of Nociception in a Rat Model of Parkinson's Disease

Lei, Jing

2020-08-01

Lei , J , Ye , G , Pertovaara , A \& You , H-J 2020 , ' Effects of Heating-needle Stimulation in Restoration of Weakened Descending Inhibition of Nociception in a Rat Model of Parkinson's Disease ' , Neuroscience , vol. 440 , pp. 249-266 . https://doi.org/10.1016/j.neuroscience.2020.05.043

http://hdl.handle.net/10138/332767

https://doi.org/10.1016/j.neuroscience.2020.05.043

cc_by_nc_nd

acceptedVersion

Downloaded from Helda, University of Helsinki institutional repository.

This is an electronic reprint of the original article.

This reprint may differ from the original in pagination and typographic detail.

Please cite the original version. 
MS. no.: NSC-20-0304

\title{
Effects of heating-needle stimulation in restoration of weakened descending inhibition of nociception in a rat model of Parkinson's disease.
}

\author{
Jing Lei ${ }^{1,3}$, Gang $\mathrm{Ye}^{2}$, Antti Pertovaara ${ }^{3}$, Hao-Jun You ${ }^{1 \#}$ \\ 1 Center for Translational Medicine Research on Sensory-Motor Diseases, Yan'an \\ University, Yan'an 716000, P.R. China \\ 2 Department of Rehabilitation, Tongji Hospital, Tongji University School of \\ Medicine, Shanghai 200065, P.R. China \\ 3 Department of Physiology, Faculty of Medicine, University of Helsinki, POB 63, \\ Helsinki 00014, Finland
}

Running title: Pain and its control in Parkinson's disease

The manuscript is an original article with 45 double-spacing print pages, 10 figures and 1 table.

\# Corresponding author:

Dr. Hao-Jun You

Center for Translational Medicine Research on Sensory-Motor Diseases

Yan'an University

ShengDi Road 580\#, Yan'an 716000

P.R. China

E-mail: haojunyou@126.com (H.-J. You) 


\begin{abstract}
Here we investigated variations of endogenous descending modulation of nociception and therapeutic effects of intramuscular (i.m.) heating-needle stimulation in early stage of Parkinson's disease (PD) induced by unilateral microinjection of $3.5 \mu 1$ of 2.5 $\mu \mathrm{g} / \mu \mathrm{l}$ 6-hydroxydopamine into the rat striatum. Paw withdrawal reflexes to noxious mechanical and heat stimuli in PD rats with and without exposure to i.m. 5.8\% saline induced muscle nociception were evaluated. Experimental PD had no influence on mechanical or heat sensitivity in the baseline condition, whereas descending facilitation was stronger and descending inhibition was weaker in PD rats than vehicle-treated or naive rats during muscle nociception $(P<0.05)$. Striatal administration of $5 \mu \mathrm{g}$ of dopamine failed to reverse the PD-associated changes in descending facilitation or inhibition, whereas dopamine in the thalamic mediodorsal (MD) nucleus and ventromedial (VM) nucleus significantly decreased the increase in descending facilitation and reversed the attenuation in descending inhibition, respectively $(P<0.05)$. I.m. $43{ }^{\circ} \mathrm{C}$ of heating-needle stimulation had no effects on the enhanced descending facilitation in PD rats, but it markedly increased descending inhibition and reversed the increase in the number of apomorphine-induced body rotations $(P<0.05)$, which effects were dose-dependently attenuated by raclopride, a dopamine 2 receptor antagonist, in the thalamic VM nucleus $(P<0.05)$. The results indicate that the early-stage PD is associated with enhanced descending facilitation and weakened descending inhibition. From clinical perspective, $43^{\circ} \mathrm{C}$ heat therapeutic
\end{abstract}


regime promises to selectively enhance descending inhibition that is accompanied by improvement of motor dysfunction in PD.

Keywords: Parkinson's disease; Muscle pain; Endogenous descending control of pain; Thalamic 'nociceptive discriminator'; Dopamine

\section{INTRODUCTION}

Parkinson's disease (PD) is a common neurodegenerative disorder that was first described as "shaking palsy" in the beginning of $19^{\text {th }}$ century. PD patients have a loss of dopamine neurons in nigrostriatal pathway and PD is characterized mainly by motor symptoms, i.e. resting tremor, bradykinesia, and rigidity (Ehringer and Hornykiewicz, 1960; Bernheimer et al., 1973; Obeso et al., 2004). More recently, non-motor manifestations of PD, such as pain, depression, sleep disturbance, and autonomic disorders, have received more attention (Chen et al., 2013; Schapira et al., 2017). With regard to sensory symptoms in PD patients, there is epidemiological evidence indicating that the prevalence of pain varies between $30 \%$ and $95 \%$, and pain is an early and even a pre-motor symptom during the development of PD (Beiske et al., 2009; Buhmann et al., 2017). Among various manifestations of pain reported in PD patients are musculoskeletal pain, dystonia, radicular pain, and central pain syndrome (Wasner and Deuschl, 2012). With respect to mechanisms underlying PD-related pain, there is accumulating experimental evidence showing that deficiency of the dopaminergic system influences a number of central structures, i.e. insular 
cortex, basal ganglia, limbic areas, thalamus, and periaqueductal gray, which have potential impact upon pain (Chudler and Dong, 1995; Burkey et al., 1999; Hagelberg et al., 2002; Wood, 2008). It has been further shown that chronic PD patients may have serious atrophy of several cortical areas such as the dorsolateral prefrontal cortex, orbitofrontal cortex, and posterior cingulate cortex that are involved in processing of emotional aspects of pain (Polli et al., 2016). Despite serious impact of PD on various central structures in modulation of pain, few studies have explored whether pain occurring in the early stage of PD is also accompanied by a dysfunction in descending facilitation and inhibition of pain.

Anatomical and functional studies have shown massive topographically-organized projections from the thalamus to the striatum that are part of the frontal cortex-basal ganglia-thalamus network involved in regulating motivation, emotional drive, and goal directed behaviors (Haber and Calzavara, 2009). With respect to descending modulation of pain, our previous study revealed the critical role of the thalamus in selective control of pain and pain hypersensitivity, i.e. hyperalgesia (You et al., 2013). Within the thalamus, two specific thalamic nuclei: the mediodorsal (MD) nucleus and the ventromedial (VM) nucleus, have been identified to function as a 'Thalamic nociceptive discriminator' that discriminates afferent barrage evoked by noxious mechanical stimulation from that evoked by noxious heat stimulation, which is of importance for determining the type of descending control that is activated (You et al., 2013, 2016). From functional perspective, thalamic MD and VM nuclei exhibit distinct roles in evoking activities of facilitatory and inhibitory controls upon noxious 
mechanically and heat-evoked nociception (Lei et al., 2011; Lei and You, 2013; Xiao et al., 2015; You et al., 2013, 2016). Most importantly, experimental evidence indicates that the thalamus-mediated endogenous descending modulation of pain is inactive or relatively 'silent' in a physiological state (You et al., 2010). Using a combination of behavioral testing and immunohistochemical methods, it has been shown that a sufficient activation of C-afferents accompanied by central temporal and spatial summation is needed to recruit thalamus-mediated descending pain modulation (Lei et al., 2015; Xiao et al., 2015; You et al., 2016). Concerning peripheral stimulation that activates descending modulation, recent experimental studies in humans and animals showed that intramuscular (i.m.) heating-needle stimulation at a noxious temperature of $46{ }^{\circ} \mathrm{C}$ elicits both descending facilitation and descending inhibition, whereas heating-needle stimulation at $43{ }^{\circ} \mathrm{C}$ initiates descending inhibition alone that is regulated by thalamic VM nucleus (You et al., 2014; Lei et al., 2017, 2020). As mentioned above, it is not yet clear whether among mechanisms underlying pain in the early-stage of PD is a change in the function of descending facilitatory or inhibitory systems. Identifying potential PD-induced changes in descending pain controls can be of particular importance for better understanding the underlying pathophysiological pain mechanisms and for developing selective mechanism-based pain therapies for PD patients.

Here we investigated whether an experimental rat model of PD induces pathophysiological changes in descending facilitation and inhibition of nociception, and explored whether dopamine or heating-needle stimulation can restore the 
PD-induced dysfunction in descending pain controls. We (1) established sustained muscle nociception as a noxious conditioning stimulus to activate descending pain controls in rats with an early-stage model of PD induced by microinjection of 6-hydroxydopamine (6-OHDA) into the striatum, (2) determined descending facilitation and inhibition of nociception mediated by specific thalamic nuclei in the early-stage PD rats, and (3) indentified whether administration of dopamine in the striatum or the thalamic MD and VM nuclei, or i.m. heating-needle stimulation at temperature of $43{ }^{\circ} \mathrm{C}$ restores the changes induced by PD in descending controls of nociception.

\section{EXPERIMENTAL PROCEDURES}

\section{Animals}

Male Sprague-Dawley rats weighing 260-300 g (10 weeks age) were provided by Animal Center of College of Medicine, Xi' an JiaoTong University. Animals were housed pairwise in plastic boxes under a 12:12 h light dark cycle (lights on at 08:00 am) at $22-26^{\circ} \mathrm{C}$ with food and water available ad libitum. All experiments were approved by the Animal Care and Use Committee of the University in accordance with the National Institute of Health Guide for the Care and Use of Laboratory Animals (NIH Publications No. 80-23) revised 1996. The experiments were reported in accordance with the ARRIVE guidelines (Kilkenny et al., 2010). The animals were acclimatized to the laboratory and habituated to the test boxes for at least 1 hour each day five days prior to testing. The rats were used only once and sacrificed at the end 
of the experiment by intraperitoneal (i.p.) injection of an overdose of sodium pentobarbital $(200 \mathrm{mg} / \mathrm{kg})$. All efforts were made to minimize the number of animals used and their suffering.

\section{Establishment of PD model by microinjection of 6-OHDA into striatum}

Injection of a bolus of $3.5 \mu \mathrm{l}$ of $2.5 \mu \mathrm{g} / \mu \mathrm{l}$ 6-OHDA into the striatum has been commonly used to be produce an experimental model of early Parkinson's disease (Przedborski et al., 1995). Rats were anesthetized with $1 \%$ sodium pentobarbital (50 mg/kg, i.p., Sigma-Aldrich, USA), and fixed with a stereotaxic frame (MP8003, RWD Life Science Co., Shenzhen, Guangdong Province, China). Sixty minutes before the intracerebral (i.c.) microinjection of 6-OHDA, the rats were treated with i.p. injection of desipramine (25 mg/kg) to protect function of noradrenergic neurons (Breese et al., 1974). A mini craniotomy was made with a dental drill to allow performing striatal injection of 6-OHDA or vehicle. A dose of $6 \mu \mathrm{g}$ of 6-OHDA (Sigma-Aldrich) diluted in $3 \mu \mathrm{l}$ of $0.9 \%$ saline with $0.2 \%$ ascorbic acid was unilaterally injected with a microsyringe into the striatum. This i.c. microinjection procedure was slowly performed with a $5 \mu \mathrm{l}$ microsyringe over a period of $2 \mathrm{~min}$. The microinjection into the striatum was performed at the following coordinates: anteroposterior (AP) $1.0 \mathrm{~mm}$ from the bregma, lateral (L) $3.0 \mathrm{~mm}$ from midline, and dorsoventral (DV) $5.0 \mathrm{~mm}$ from the cranium (Paxinos and Watson, 1998). Rats in control group were i.c. injected with $3 \mu \mathrm{l}$ of vehicle consisting of $0.9 \%$ saline with $0.2 \%$ ascorbic acid. At the end of injection, the microsyringe remained in place for an additional $5 \mathrm{~min}$ to avoid 
backflow of the solution, after which it was slowly withdrawn and the skull was closed with dental cement. Then, the animals were treated with antibiotics and observed until fully recovered from anesthesia. Animals showing severe permanent motor dysfunction were excluded from the remaining experiments (For details, see Rota-rod test).

\section{Rotation test for confirming PD-like motor disorder}

Two weeks after unilateral striatal 6-OHDA lesion, the rats were administered subcutaneously with apomorphine $(0.5 \mathrm{mg} / \mathrm{kg})$, and the rotation behavior was recorded and analyzed. The recording of rotation behavior started after the administration of apomorphine and lasted for 30 minutes. The rotation rate was quantified as the number of $180^{\circ}$ turns contralateral to the side of the injury. The rat was considered to have a PD-like motor disorder when the number of rotations induced by apomorphine reached 100 turns $/ 30 \mathrm{~min}$. To reduce stress, the rats were habituated for $30 \mathrm{~min}$ per day before the rotation test. Animals injected with 6-OHDA that did not present asymmetric rotation behavior were excluded from the study. In the current study, 6 rats were excluded due to failure to show asymmetric rotation behavior following apomorphine treatment. For comparison, naive rats and rats with a striatal sham lesion (striatal vehicle injection) were also assessed in the rotation test.

Biochemical analyses by high-performance liquid chromatography (HPLC)

We determined concentration of dopamine in the lesioned striatum in an additional experiment by means of HPLC and an electrochemical approach. The 
lesion area in the striatum was removed and stored in liquid nitrogen. For HPLC assessments, the samples were weighed and homogenized in $150 \mu \mathrm{l} 0.4 \mathrm{M}$ perchloric acid, followed by centrifugation at the speed of $160,00 \mathrm{rpm}$ for $15 \mathrm{~min}$ at $4{ }^{\circ} \mathrm{C}$. After centrifugation, a volume of $120 \mu \mathrm{l}$ of the supernatant was transferred to a test tube, and $30 \mu \mathrm{l}$ of liquid containing $20 \mathrm{mM}$ citromalic acid-potassium, $300 \mathrm{mM}$ dipotassium phosphate, and $2 \mathrm{mM}$ EDTA-2Na were then added in the test tube. Then, followed by another centrifugation at the same speed, $100 \mu$ samples of the supernatant were assayed for dopamine and its metabolites by HPLC with an electrochemical detector (The potential was adjusted to $0.7 \mathrm{~V}$ versus the reference electrode ( $\mathrm{Ag}-\mathrm{AgCl})$; the sensitivity was set at $1 \mathrm{nA})$. Tissue containing dopamine in striatum was expressed as $\mu \mathrm{g} / \mathrm{g}$ wet tissue $(\mu \mathrm{g} / \mathrm{g} \mathrm{WW})$.

\section{Muscle nociception induced by intramuscular (i.m.) injection of hypertonic saline}

As described elsewhere (You et al., 2010), 5.8 \% saline-induced sustained muscle nociception was used as a noxious conditioning stimulus to active the 'silent' or inactive descending controls. In the present study, 3 weeks after the striatal injection of 6-OHDA or vehicle, a volume of $0.2 \mathrm{ml} 5.8 \%$ hypertonic saline was injected into the gastrocnemius (GS) muscle of the hind limb contralateral to the striatal microinjection in order to establish muscle nociception. The i.m. injection site was in the middle part of the GS muscle, and the depth of the injection was about $0.5 \mathrm{~cm}$. The i.m. injection procedure was performed manually and lasted more than $30 \mathrm{~s}$. A volume of $0.2 \mathrm{ml} 0.9 \%$ saline served as a control in the current study. 


\section{I.c. microinjection of drugs}

A chronic guide cannula was installed for microinjections of dopaminergic compounds into the thalamic MD or VM nucleus or the striatum in awake animals. As described elsewhere (You et al., 2013), a craniotomy was performed with a dental drill in order to install an i.c. cannula. The guide cannula (OD: $0.35 \mathrm{~mm}$; ID: 0.25 mm; RWD Life Science Co., Shenzhen, China) was advanced stereotactically into the thalamic MD or VM nucleus, or the striatum at the following coordinates: MD nucleus: AP -(2.56-2.8) mm, L $0.6 \mathrm{~mm}$, DV $5.4 \mathrm{~mm}$; VM nucleus: AP -(2.56-2.8) mm, L 1.4-1.6 mm, DV $7.3 \mathrm{~mm}$; and striatum: AP $1 \mathrm{~mm}$, L $3 \mathrm{~mm}$, DV $5 \mathrm{~mm}$. After the installation of the guide cannula, the cannula was fixed with dental cement, the wound was washed with sterile $0.9 \%$ saline, wound area treated with antibiotics, and the wound was closed. The animals were then put back to the home cage for a 7 days' recovery during which the animals' behavior and motor function were frequently monitored. Animals showing clear impairments in motor behavior were excluded.

To assess whether dopamine can restore dysfunction of descending controls, a bolus of $0.5 \mu \mathrm{l}$ of $5 \mu \mathrm{g}$ dopamine was injected into the thalamic MD nucleus, VM nucleus, or striatum. In previous studies, administration of 0.05-5 $\mu \mathrm{g}$ of the dopamine D2 receptor antagonist raclopride into the brain has effectively depressed dopamine-mediated behavior (Boss et al., 1988). To assess the role of endogenous dopamine acting on the dopamine D2 receptor in the thalamic VM nucleus, a dose of 0.1-2.5 $\mu \mathrm{g}$ of the dopamine D2 receptor antagonist $\mathrm{S}(-)$-Raclopride (+)-tartrate salt (Sigma-Aldrich Chemie Gmbh, Germany) was freshly prepared and dissolved in 
$0.9 \%$ saline. One day after the i.m. injection of $5.8 \%$ saline into the GS muscle, a bolus of $0.5 \mu$ solution containing raclopride or vehicle was injected through the i.c. cannula using a $1 \mu \mathrm{l}$ microsyringe while the rat was gently restrained by the experimenter's hand. All drugs were slowly infused at a constant speed over a $30 \mathrm{~s}$ period. Effects by i.c. administrations of dopamine, raclopride or vehicle were assessed during a period lasting up to $4 \mathrm{~h}$ after the administration.

After finishing the experiment, the drug injection site was marked by microinjection with Pontamine Sky Blue dye $(0.5 \mu \mathrm{l} ; 2 \%$ in $0.5 \mathrm{M}$ sodium acetate acid).

\section{Rota-rod test}

Motor coordination, balance and locomotor performance were examined by means of a Rota-rod treadmill (Model 755, IITC, USA) described elsewhere (You et al., 2010, 2013). The rotating speed of the treadmill was gradually increased from 5 to 30 r.p.m. for $30 \mathrm{~s}$ and maintained for another $120 \mathrm{~s}$ at 30 r.p.m. Rats with a motor dysfunction (drop latency $<5 \mathrm{~s}$ ) after either i.c. injections or the implantation of i.c. guide cannula were excluded from the remaining experiments. In the present study, 6 animals were excluded because their drop latencies from the Rota-rod treadmill were below $5 \mathrm{~s}$.

I.m. heating-needle stimulation 
Following the procedure described in our previous study (You et al., 2014), 1 day after the i.m. injection of $5.8 \%$ saline rats were anaesthetized by mask inhalation of isoflurane (4 \% isoflurane in $96 \%$ oxygen), followed by $1 \%$ isoflurane in $99 \%$ oxygen for the maintenance of anaesthesia during the i.m. heating-needle stimulation. Heating-needle stimulation was applied using a concentric stainless-steel heating-needle (diameter, $1.05 \mathrm{~mm}$; length, $30 \mathrm{~mm}$ ), which was connected to and feedback-controlled by an inner-heating therapeutic device (Model: NWX-1, Acuceuticals Co., Ltd, Shanghai, China). Inside the heating-needle is a heating element and a temperature probe, which detects temperature at an accuracy of \pm $0.25^{\circ} \mathrm{C}$. The heating-needle was inserted into the middle part of the GS muscle ipsilateral to the side of the i.m injection of hypertonic saline. The depth of the needle insertion was about $0.5 \mathrm{~cm}$. The temperature of the heating-needle used in the present study was set at $43{ }^{\circ} \mathrm{C}$, and the duration of heating-needle stimulation was 30 minutes. These stimulation parameters have not produced pain-related behavior in animals or pain sensation in humans (You et al., 2014; Lei et al., 2017).

\section{Experimental design}

Animals were randomly divided into different experimental groups, each consisting of 10 rats. The investigator conducting the behavioral measurements was blinded to the experimental group; i.e. the experimenter was not aware whether the studied animal belonged to the "striatal 6-OHDA lesion" group or the "striatal vehicle lesion" group, or whether the animal received i.c. dopamine $\mathrm{D} 2$ receptor antagonist or $0.9 \%$ 
saline, etc.

In the present study, the body weight measurement and Rota-rod test were performed prior to, and 7-14 d after the i.c. 6-OHDA injection into the striatum, whereas apomorphine-induced rotation was tested $14 \mathrm{~d}$ after the 6-OHDA injection. The entire study was divided into different sessions. In session 1, paw withdrawal reflexes evoked by noxious mechanical and heat stimuli were evaluated prior to and 1-3 weeks after the i.c. 6-OHDA injection. In session 2, the effect by supplemental doses of dopamine into the thalamic VM/MD nuclei on descending modulation of paw withdrawal reflexes was studied during hypertonic saline-induced muscle nociception in animals that were exposed 3 weeks earlier to striatal 6-OHDA treatment. In session 3, animals that were 3 weeks earlier exposed to striatal 6-OHDA treatment were given heating-needle stimulation for $30 \mathrm{~min}$ at the temperature of 43 ${ }^{\circ} \mathrm{C}$ in the GS muscle ipsilateral to the i.m. hypertonic saline injection together with i.c. injection of vehicle or raclopride to assess whether peripheral stimulation might restore the function of descending controls and whether the restoration is mediated by thalamic dopamine D2 receptors. Diagram of the experimental design is shown in Figure 1.

\section{Measurement of mechanical and heat sensitivity}

For the measurement of mechanically evoked paw withdrawal response, rats were placed in individual Plexiglas chambers with mesh floors underneath and transparent top covers $(20 \times 20 \times 25 \mathrm{~cm})$. A hand-held electronic von Frey device $(2290$ 
Electrovonfrey ${ }^{\circledR}$, IITC, Woodland Hills, CA, USA) with a rigid filament was used to detect the mechanical paw withdrawal threshold. According to the mapping of the withdrawal field of the gastrocnemius muscle (You et al., 2010), the filament was applied to the heel part of the hind paw until a foot-withdrawal response was elicited, indicating that the mechanical threshold $(\mathrm{g})$ and the cut-off force of $90 \mathrm{~g}$ had been achieved.

Noxious heat-evoked paw withdrawal response was determined using a 390G plantar stimulator Analgesia Meter (IITC, Woodland Hills, CA). The rats were placed individually into a Plexiglas cubicle placed onto a constant temperature-controlled transparent glass used to avoid temperature sink from the tested hind paws. The radiant heat stimulus was a high-intensity beam (setting $=30-40 \%$ intensity) aimed at the heel part of the hind paw. The latency of the hind paw withdrawal was determined as the time from the onset of noxious heat stimulation to withdrawal of the tested hind paw. Latency of the paw withdrawal reflex was initially around 10-11 seconds, which was considered the baseline response. Heat stimulus of 10-11 s duration evoked a painful, but tolerant sensation when applied to the experimenter's hand. To avoid excessive tissue injury, the cut-off latency for heat stimulation was 20 seconds.

The paw withdrawal thresholds to noxious mechanical and heat stimuli were tested for both ipsilateral and contralateral heel part of hind paws before, 7 days after and every 2 days during 7-21 days after the striatal 6-OHDA lesion. Besides, the paw withdrawal thresholds were observed bilaterally 30 minutes prior to, and 30 minutes, 2-4 hours, 1-7 days post the i.m. administration of hypertonic saline. At each time 
point, hind paws were bilaterally tested in three consecutive trials, with at least a 30-s interval between the trials. The mean of the three trials at each time point was considered the mechanical paw withdrawal threshold $(\mathrm{g})$ and thermal paw withdrawal latency (s). A reduction in threshold/latency of the paw withdrawal response was considered to represent hyperalgesia and an increase in threshold/latency was considered to represent hypoalgesia.

Since noxious test stimuli used to evoke withdrawal responses in the present study were applied to a skin site that was in an intact area (outside of the region of the GS muscle treated with hypertonic saline), hyperalgesia or hypoalgesia observed in the present study was due to central mechanisms; i.e., they represented secondary hyperalgesia and secondary hypoalgesia.

\section{Histology for identification of the placement of the cannula}

At the end of behavioral testing, the animals that had an i.c. cannula were anaesthetized by sodium pentobarbital $(50 \mathrm{mg} / \mathrm{kg}$, i.p.) and transcardially perfused with $10 \%$ formalin. The brain was then isolated and stored in $30 \%$ sucrose for 2 days. Freezing serial sections (50 $\mu \mathrm{m}$ thickness) were cut in the coronal plane and stained with Nissl stain, and the brain sections were screened under a microscope (Leica, Germany). Schematic reconstruction of the injection sites was drawn according to the stereotaxic atlas of rats (Paxinos and Watson, 1998). In the brain, microinjection of $0.5 \mu \mathrm{l}$ solution spread from the injection site about $0.4 \mathrm{~mm}$. The locations of the brain injections in the brain were assessed in a blinded fashion; i.e., the experimenter 
determining the location of the cannula tip was not aware of the behavioral results.

\section{Statistical analysis}

For quality control, the concepts of measurement error, i.e. cutoff value, execution error, sample size, and incorrect distributional assumption were strictly considered throughout the entire experiments to avoid possible outliers (Grant and Leavenworth, 1972). In the current study, all results were expressed as means \pm SEM. The data were analyzed using SigmaStat ${ }^{\mathrm{TM}}$ (Systat Software Inc., California, USA). Statistical comparisons were made using Student 's $t$-test for biochemical data. When comparing more than two groups, statistical calculations were performed using either one-way or two-way repeated measures of analysis of variance (one-way ANOVA or two-way RM ANOVA, respectively) followed by a post-hoc Bonferroni t-test. $P<0.05$ was considered to represent statistically significant difference.

\section{RESULTS}

I.c. infusion of 6-OHDA into the striatum and its effects on nociception.

To assess whether striatal 6-OHDA treatment had induced a PD-like motor disorder, the effect of apomorphine on rotation behavior was determined. Following apomorphine treatment $(0.5 \mathrm{mg} / \mathrm{kg}$, i.p. $)$, rats with unilateral injection of 6-OHDA into the striatum exhibited pronounced contralateral rotation to the chemical lesion side compared with the apomorphine-induce rotation behavior of the control groups (total no. of rotations: $156 \pm 18.4$ (6-OHDA treated rats) vs $27 \pm 4.5$ (vehicle treated rats) vs $23 \pm 3.3$ (naive rats) $(P<0.001$, one-way ANOVA). The Rota-rod test was 
performed to examine motor coordination in the 6-OHDA-lesioned rats. As shown in table 1, no significant changes in the time spent on the Rota-rod were found in the 6-OHDA-lesioned rats compared with those of sham-lesioned (vehicle-treated) rats or naive rats without treatment $(P=0.41$, one-way ANOVA). Body weight was used as a marker reflecting the physical health of the PD model animals. In the present study, no significant differences in body weight were found among 6-OHDA-lesioned rats, vehicle-lesioned rats, and naive rats $(P=0.53$, one-way ANOVA).

Figure 2 shows paw withdrawal responses evoked by noxious mechanical and heat stimulation prior to, and 7-21 d after the i.c. administration of either 6-OHDA or vehicle ( $0.9 \%$ saline with $0.2 \%$ ascorbic acid). No significant changes of paw withdrawal responses to noxious mechanical and heat stimuli were found in the 6-OHDA-lesioned rats compared with the naive control rats or rats treated with intrastriatal injection of vehicle (Fig. 2, $P=0.36$, two-way ANOVA).

In an additional neurochemical experiment, we determined the concentration of dopamine in striatum 2-4 weeks after the striatal administration of 6-OHDA. Two weeks after the striatal 6-OHDA lesion, the level of dopamine was significantly reduced to $7.5 \pm 1.5 \mu \mathrm{g} / \mathrm{g} \mathrm{WW}$ compared with that in naive rats or rats exposed to the striatal vehicle treatment (naive rat: $19.2 \pm 1.6 \mu \mathrm{g} / \mathrm{g} \mathrm{WW}$; vehicle treatment rats: 18.9 $\pm 1.6 \mu \mathrm{g} / \mathrm{g} \mathrm{WW} ; \mathrm{n}=5, P<0.001$, Student's t-test). This neurotoxin effect of 6-OHDA remained at the same level over the 4 weeks observation period, and no significant differences in the level of dopamine were found in dopamine levels measured 2 weeks, 3 weeks, and 4 weeks following the striatal 6-OHDA treatment.

Variable paw withdrawal reflex during muscle nociception in PD rats and naive rats. 
Sustained muscle nociception induced by $5.8 \%$ saline injection was previously used as a noxious conditioning stimulation to induce activation of descending pain controls and to allow studying descending control of nociception (You et al., 2010; Lei et al., 2011). In the present study, paw withdrawal reflexes to mechanical and heat stimuli were evaluated bilaterally $30 \mathrm{~min}$ prior to, and $30 \mathrm{~min}, 2-4 \mathrm{~h}$ and $1-7 \mathrm{~d}$ after the unilateral i.m. injection of either $0.9 \%$ saline (physiological saline) or $5.8 \%$ saline (hypertonic saline) into the GS muscle. Following i.m. injection of $0.9 \%$ saline, no significant changes in mechanically evoked withdrawal reflexes were found in naive or vehicle-lesioned rats. In marked contrast, the mechanically evoked withdrawal reflex response was significantly enhanced (threshold decreased) in both hind paws of the 6-OHDA-treated rats after the i.m. injection of $0.9 \%$ saline (Ipsilateral to the lesion: drug effect $F(1,9)=7.14, \mathrm{P}=0.036$, drug $\times$ time interaction $F(9,81)=2.52, \mathrm{P}$ $=0.023$; Contralateral to the lesion: drug effect $F(1,9)=7.18, \mathrm{P}=0.035$, drug $\times$ time interaction $F(9,81)=2.54, \mathrm{P}=0.022$; two-way ANOVA, Fig. 3a-b). Mechanical hyperalgesia in 6-OHDA-treated rats was initiated $4 \mathrm{~h}$ after the i.m injection of $0.9 \%$ saline and lasted for 5 days.

Following the i.m injection with $5.8 \%$ saline into the GS muscle, early-onset and long-lasting mechanical hyperalgesia and late-onset, long-term heat hypoalgesia were observed in naive control rats and vehicle-lesioned (i.e., with a vehicle-treated striatum) rats, which findings are consistent with previous results (You et al., 2010; Lei et al., 2011). Compared with the vehicle-lesioned rats, mechanical hyperalgesia was significantly enhanced (threshold decreased) in 6-OHDA treated PD rats (Ipsilateral to the lesion: drug effect $F(1,9)=7.22, \mathrm{P}=0.031$, drug $\times$ time interaction $F(9,81)=2.51, \mathrm{P}=0.024$; Contralateral to the lesion: drug effect $F(1,9)=7.24, \mathrm{P}=$ 0.032, drug $\times$ time interaction $F(9,81)=2.55, \mathrm{P}=0.03$; two-way ANOVA, Fig. 3a-b) 
In contrast to significant long-term heat hypoalgesia induced by the i.m. injection of $5.8 \%$ saline in naive rats and rats with the striatal vehicle-treatment, in rats with the striatal 6-OHDA treatment the i.m. injection of $5.8 \%$ saline only slightly and non-significantly prolonged noxious heat-evoked paw withdrawal responses (Ipsilateral to the lesion: drug effect $F(1,9)=3.16, \mathrm{P}=0.12$, drug $\times$ time interaction $F(6,54)=1.873, \mathrm{P}=0.09 ;$ Contralateral to the lesion: drug effect $F(1,9)=3.13, \mathrm{P}=$ 0.15, drug $\times$ time interaction $F(6,54)=1.902, \mathrm{P}=0.105$; two-way ANOVA, Fig. $3 c-d)$.

Effects of i.c. supplementation of dopamine on nociception during muscle nociception in $P D$ rats.

One day after the i.m. injection of $5.8 \%$ saline, a dose of $5 \mu \mathrm{g}$ of dopamine was microinjected into the contralateral striatum of either PD rats or naive rats. Neither mechanical paw withdrawal threshold (Ipsilateral to the lesion: drug effect $F(1,9)=$ 2.23, $\mathrm{P}=0.33$, drug $\times$ time interaction $F(4,36)=2.11, \mathrm{P}=0.09 ;$ Contralateral to the lesion: drug effect $F(1,9)=2.19, \mathrm{P}=0.34$, drug $\times$ time interaction $F(4,36)=2.09, \mathrm{P}$ $=0.13$; two-way ANOVA, Fig. 4a-b) nor latency of the heat-evoked paw withdrawal (Ipsilateral to the lesion: drug effect $F(1,9)=2.02, \mathrm{P}=0.42$, drug $\times$ time interaction $F(4,36)=2.08, \mathrm{P}=0.17$; Contralateral to the lesion: drug effect $F(1,9)=2.21, \mathrm{P}=$ 0.35 , drug $\times$ time interaction $F(4,36)=2.09, \mathrm{P}=0.16$; two-way ANOVA, Fig. 4c-d) was influenced in PD rats. Likewise, i.c. administration of dopamine failed to influence mechanically and heat evoked paw withdrawal reflexes in naive rats $(P>$ 0.05, two-way ANOVA, Fig. 4).

We also microinjected dopamine into the contralateral thalamic MD nucleus, which caused bilateral attenuation of the hypertonic saline-induced mechanical 
hyperalgesia in PD rats (Ipsilateral to the lesion: drug effect $F(1,9)=8.23, \mathrm{P}=0.02$, drug $\times$ time interaction $F(4,36)=3.21, \mathrm{P}=0.03$; Contralateral to the lesion: drug effect $F(1,9)=8.27, \mathrm{P}=0.018$, drug $\times$ time interaction $F(4,36)=3.24, \mathrm{P}=0.029$; Fig. 5a-b, two-way ANOVA). Likewise, i.c. microinjection of dopamine into the thalamic VM nucleus induced a significant prolongation of the heat-evoked paw withdrawal latency within $1 \mathrm{~h}$ (i.e., enhancement of the hypertonic saline-induced heat hypoalgesia) (Ipsilateral to the lesion: drug effect $F(1,9)=8.19, \mathrm{P}=0.03$, drug $\times$ time interaction $F(4,36)=3.25, \mathrm{P}=0.027$; Contralateral to the lesion: $\operatorname{drug}$ effect $F(1,9)=$ 8.31, $\mathrm{P}=0.017$, drug $\times$ time interaction $F(4,36)=3.26, \mathrm{P}=0.024$; Fig. $6 \mathrm{c}-\mathrm{d}$, two-way ANOVA). In contrast, dopamine administration into the MD nucleus had no influence on heat hypoalgesia, nor did dopamine administration into the VM nucleus influence mechanical hyperalgesia (Fig. 5c-d and Fig. 6a-b; $P>0.05$, two-way ANOVA).

Effect of i.m. $43^{\circ} \mathrm{C}$ heating-needle stimulation on descending modulation of nociception in PD rats.

To assess whether heating-needle stimulation of the GS muscle at a temperature of $43{ }^{\circ} \mathrm{C}$ influences descending modulation of nociception in baseline condition in PD rats, effect of heating-needle stimulation on paw withdrawal responses evoked by noxious mechanical and heat stimuli were determined in PD animals without accompanying noxious conditioning stimulation (i.e. without accompanying i.m. injection of hypertonic saline). Heating-needle stimulation applied to the GS muscle for $15-45 \mathrm{~min}$ at a temperature of $43{ }^{\circ} \mathrm{C}$ failed to have any effects on the mechanically evoked paw withdrawal reflex ipsi- or contralateral to the heating-needle-stimulation $(P>0.05$, Fig. 7a-b). However, the noxious heat-evoked paw withdrawal latency was 
bilaterally increased (heat hypoalgesia) when the heating-needle stimulation at a temperature of $43{ }^{\circ} \mathrm{C}$ lasted for $30-45 \min \left(30 \min 43{ }^{\circ} \mathrm{C}\right.$ heating-needle stimulation: ipsilateral to the lesion $F(1,9)=8.23, \mathrm{P}=0.02$, treatment $\times$ time interaction $F(6,54)=$ 3.10, $\mathrm{P}=0.015$; Contralateral to the lesion effect $F(1,9)=8.34, \mathrm{P}=0.019$, treatment $\times$ time interaction $F(6,54)=3.13, \mathrm{P}=0.013)\left(45 \min 43{ }^{\circ} \mathrm{C}\right.$ heating-needle stimulation: ipsilateral to the lesion treatment effect $F(1,9)=8.41, \mathrm{P}=0.015$, treatment $\times$ time interaction $F(6,54)=3.17, \mathrm{P}=0.012$; Contralateral to the lesion effect $F(1,9)=8.44$, $\mathrm{P}=0.014$, treatment $\times$ time interaction $F(6,54)=3.12, \mathrm{P}=0.014)$, but not when it lasted 15 min (Fig. 7c-d, two-way ANOVA). The prolonged paw withdrawal latency declined gradually to the baseline level within $4-5 \mathrm{~d}$. In contrast to the effects of i.m. heating-needle stimulation at a temperature of $43{ }^{\circ} \mathrm{C}$, i.m. needle stimulation alone (without heating of the needles) for a period of $45 \mathrm{~min}$ had no effects on mechanically or heat-evoked withdrawal responses in the ipsi- or contralateral limb of PD rats (Fig. 7).

We further investigated whether the i.m. heating-needle stimulation at the temperature of $43{ }^{\circ} \mathrm{C}$ influences mechanical or heat nociception in PD rats, in which noxious conditioning stimulation (i.m. administration of $5.8 \%$ saline) has been used to induce tonic activation of descending modulation of nociception. In PD rats, i.m. administration of $5.8 \%$ saline induced muscle nociception and bilateral mechanical hyperalgesia and heat hypoalgesia. Mechanical hyperalgesia was not influenced by i.m. heating-needle-stimulation at a temperature of $43^{\circ} \mathrm{C}$ for $30 \mathrm{~min}(P>0.05$, two-way ANOVA, Fig. 8a-b), whereas heat hypoalgesia was bilaterally increased as shown by significantly increased paw withdrawal latencies in PD rats (Ipsilateral to the lesion effects $F(1,9)=8.22, \mathrm{P}=0.02$, treatment $\times$ time interaction $F(6,54)=3.31$, 
$\mathrm{P}=0.011$; Contralateral to the lesion effect $F(1,9)=8.31, \mathrm{P}=0.019$, treatment $\times$ time interaction $F(6,54)=3.33, \mathrm{P}=0.01)$ (Fig. 8c-d, two-way ANOVA).

To assess whether dopamine D2 receptors in the thalamic VM nucleus were involved in mediating the heating-needle stimulation-induced enhancement of heat hypoalgesia in PD rats with sustained muscle nociception, different doses of the dopamine D2 receptor antagonist raclopride $(0.1-2.5 \mu \mathrm{g} / 0.5 \mu \mathrm{l})$ were microinjected into the thalamic VM nucleus of PD rats one day after the i.m. heating-needle stimulation at a temperature of $43{ }^{\circ} \mathrm{C}$ for $30 \mathrm{~min}$. The increased descending inhibition elicited by the i.m. heating-needle stimulation was dose-dependently reversed by raclopride applied to the thalamic VM nucleus $(0.5 \mu \mathrm{g}$ raclopride: ipsilateral to the lesion $F(1,9)=6.3, \mathrm{P}=0.03$, drug $\times$ time interaction $F(4,36)=3.22, \mathrm{P}=0.031$; Contralateral to the lesion $F(1,9)=6.33, \mathrm{P}=0.029$, drug $\times$ time interaction $F(4,36)=$ $3.24, \mathrm{P}=0.03)(2.5 \mu \mathrm{g}$ raclopride: ipsilateral to the lesion $F(1,9)=9.91, \mathrm{P}=0.013$, drug $\times$ time interaction $F(4,36)=3.26, \mathrm{P}=0.027$; Contralateral to the lesion $F(1,9)=$ 9.94, $\mathrm{P}=0.012$, drug $\times$ time interaction $F(4,36)=3.25, \mathrm{P}=0.028)$ (Fig. 9, two-way

\section{ANOVA).}

We further explored whether the i.m. heating-needle stimulation at a temperature of $43{ }^{\circ} \mathrm{C}$ influences apomorphine-induced rotation behavior in the 6-OHDA-induced rat model of PD. Heating-needle stimulation at a temperature of $43{ }^{\circ} \mathrm{C}$ for $30 \mathrm{~min}$ decreased the number of apomorphine-induced rotations in 6-OHDA-treated animals from $156 \pm 58.2$ rotations to $31 \pm 12.9$ rotations $(\mathrm{n}=10, P<0.001$, Bonferroni-corrected $t$-test). In addition, this decrease in the apomorphine-induced rotation behavior of PD rats induced by heating-needle stimulation was significantly reversed by administration of raclopride into the thalamic VM nucleus in a dose-dependent manner (data not shown). 
Figure 10 shows the schematic reconstructions of the 6-OHDA-induced chemical lesions in the striatum as well as sites in the striatum or thalamic MD and VM nuclei into which other studied drugs were microinjected. All the brain injection sites were contralateral to the i.m. heating-needle stimulation.

\section{DISCUSSION}

In the present study, we assessed whether experimental rat model of early-stage PD induced by striatal 6-OHDA treatment influences descending inhibition or descending facilitation of nociception. Among main findings is that descending modulation of nociception is imbalanced in the early-stage PD as shown by enhanced descending facilitation and decreased descending inhibition. The PD-induced abnormality in endogenous descending controls was attenuated by supplementation of dopamine into the thalamic MD and VM nuclei, but not the striatum. In control rats, striatal dopamine supplement had no effect. These results suggest that the dopamine-induced regulation of descending modulation of nociception in PD probably takes place in the thalamus rather than the striatum. I.m. heating-needle stimulation at a temperature of $43{ }^{\circ} \mathrm{C}$ reversed the $\mathrm{PD}$-induced weakening of descending inhibition through mechanisms involving dopamine D2 receptors in the thalamic VM nucleus. This finding provides a novel insight to an alternative, non-pharmacological intervention therapy for symptoms induced by early-stage PD.

\section{$P D$ and 6-OHDA-induced PD model in animals}

It is well known that PD is a human neurodegenerative disorder, which is 
characterized by a progressive and massive degeneration of the dopaminergic neurons in the substantia nigra. The loss of dopamine in their terminal projection area, i.e. the striatum, causes the characteristic neurological symptoms of the disease (Fahn, 1988). The compound 6-OHDA, a hydroxylated analogue of dopamine, was identified in the early 1960s (Senoh and Witkop, 1959; Senoh et al., 1959). Administration of 6-OHDA has been widely used to chemically lesion the nigrostriatal dopaminergic system and to produce an experimental model of PD in animals (Hökfelt and Ungerstedt, 1973; Mokry, 1995; Deumens et al., 2002; Jackson-Lewis et al., 2012; Buhidma et al., 2020). It has to be borne in mind that the magnitude and characteristics of neurodegeneration induced by administration of 6-OHDA into the brain are significantly affected by the site of injection (Agid et al., 1973; Yuan et al., 2005). Unilateral injection of 6-OHDA into the medial forebrain bundle or substantia nigra in the rat shows an immediate and almost full destruction of dopamine neurons in the substantia nigra pars compacta and the ventral tegmental area, resulting in nearly total depletion of dopamine and up-regulation of the postsynaptic dopamine receptors in the striatum and the primary injection site. Such a treatment produces a model that well mimics the end-stage of PD (Faull and Laverty, 1969; Kaakkola and Teräväinen, 1990). In contrast, delivering 6-OHDA into the striatum, as in the present study, induces a slowly progressing partial damage to the nigrostriatal structure involving both dopaminergic nerve terminals innervating the striatum and retrogradely dopaminergic cell bodies (Berger et al., 1991; Sauer and Oertel, 1994). The damage of dopaminergic neurons following striatal 6-OHDA administration 
progresses in a retrograde fashion over a period of up to 3 weeks, and a stable lesion lasts for at least 12 weeks (Sauer and Oertel 1994; Przedborski et al. 1995) and represents an early-stage PD model (Yuan et al., 2005).

At doses higher than $6 \mu \mathrm{g}, 6$-OHDA produces a significant dopamine depletion, and 6-14 $\mu \mathrm{g}$ of 6-OHDA is generally considered to be the most effective dose in eliciting at least $40-60 \%$ depletion of dopamine that is accompanied by D-amphetamine/apomorphine-induced rotation behavior (Ishida et al., 2005; Leikas et al., 2017; Miyanishia et al, 2019). In line with this, unilateral striatal lesion with $6 \mu \mathrm{g}$ of 6-OHDA mimics clinical evidence of early deficits in isometric force control that affects the daily life of early-stage PD patients (Bethel-Brown et al., 2011). In the current study, 2 weeks after the striatal 6-OHDA lesion, robust apomorphine-induced rotation was found, which is consistent with earlier findings. In addition to the apomorphine-induced rotation, the Rota-rod test and body weight gain have often been employed as indexes of motor deficits and progressively declining dopamine levels in PD model animals (Iancu et al., 2005; Jalewa et al., 2017; Miyanishi et al., 2019). Moreover, a number of studies with 6-OHDA-treated rats have shown decreased mechanical and thermal nociceptive thresholds (e.g. Zengin-Toktas et al., 2013; Takeda et al., 2014). However, in the present study, PD animals showed no significant abnormalities in the Rota-rod test, body weight nor in baseline withdrawal thresholds evoked by mechanical or heat stimulation when compared with naive animals or animals that received striatal vehicle treatment. It has been reported that the magnitude of the movement deficit in forelimb stepping and skilled paw use is 
most significant when 6-OHDA is injected into three or four brain locations, instead of a single site (Kirik et al., 1998). This earlier finding raises the possibility that variability in the magnitude of 6-OHDA-induced dopamine depletion may explain the differences in motor and sensory changes between studies. It is also noteworthy that in the present study, the Rota-rod test and body weight development were not different between PD and control rats indicating that motor coordination and feeding behavior, respectively, are not affected in the experimental rat model of early-stage PD, in line with earlier results in animals with early-stage of PD (Domenici et al., 2019).

Descending modulation: facilitation and inhibition of pain in rats with $P D$

Since descending modulation of pain may not be active in a physiological state, muscle nociception induced by i.m. injection of $5.8 \%$ saline was used as a noxious conditioning stimulus to recruit tonic activation of descending controls. As in previous studies, magnitude of secondary mechanical hyperalgesia induced by muscle nociception represented activity level of descending facilitatory controls and secondary heat hypoalgesia induced by muscle nociception represented activity level of descending inhibitory controls (You et al., 2010; Lei et al., 2011). A novel finding in the present study is that descending facilitation is enhanced and descending inhibition decreased in PD rats exposed to i.m. administration of $5.8 \%$ saline. Additionally, enhancement of mechanically evoked nociception was found after i.m. injection of $0.9 \%$ saline in PD rats (figure 3), unlike in naive rats of the present and our previous study (Lei et al., 2011). Importantly, administration of dopamine into the 
thalamic MD/VM nuclei, but not the striatum, reversed the PD-induced changes in descending controls; i.e. both the increase in descending facilitation and the decrease in descending inhibition was reversed. Interestingly, thalamic subnuclei had partly different roles in dopaminergic regulation of descending controls in PD animals as shown by the finding that dopamine administration into the thalamic MD nucleus reversed the increase in descending facilitation, whereas dopamine administration into the thalamic VM nucleus reversed the decrease in descending inhibition. Both the increase in descending facilitation and the decrease in descending inhibition observed in PD animals is a pronociceptive change. Based on this, it may be proposed that a pronociceptive change in descending controls is among mechanisms contributing to pain in PD patients.

Concerning underlying neurotransmitter mechanisms, there are reports showing that dysfunction of the noradrenergic, serotonergic, and non-dopaminergic (e.g., opioid) system has a complex role in governing non-motor symptoms, i.e. pain, in humans and animals with PD (Tong et al., 2015; Cao et al., 2016; Campos et al., 2019). Accordingly, experiments addressing complex role of different signaling pathways in descending modulation of pain in the early stage of PD are required in the future.

Effect of Heating-needle stimulation on descending control of pain in PD

Our earlier human and animal studies indicate that i.m. heating-needle stimulation at a temperature of $43{ }^{\circ} \mathrm{C}$ for $30-45$ minutes activates in a tonic fashion descending 
inhibition alone, without accompanying activation of descending facilitation (You et al., 2014; Lei et al., 2017). In the current study, PD did not influence baseline nociception, but recruitment of descending inhibition by hypertonic saline-induced muscle nociception was reduced in PD rats. Importantly, heating-needle stimulation at the temperature of $43^{\circ} \mathrm{C}$ significantly increased descending inhibition in PD rats as revealed by the increase in secondary heat hypoalgesia; i.e. heating-needle stimulation reversed the PD-induced weakening in descending inhibition of nociception. Additionally, microinjection of dopamine into the thalamic VM nucleus of PD rats also restored the weakened descending inhibition, while microinjection of a selective dopamine D2 receptor antagonist into the thalamic VM nucleus reversed the heating-needle stimulation-induced restoration of weakened descending inhibition in PD. These findings indicate that dopaminergic mechanisms acting on the dopamine D2 receptor in the thalamic VM nucleus are involved in the PD-induced decrease of descending inhibition and its restoration by heating-needle stimulation. The other PD-induced abnormality in descending control of nociception, increase in descending facilitation shown as increased secondary mechanical hyperalgesia that was reversed by microinjection of dopamine into the thalamic MD nucleus, however, was not influenced by heating-needle stimulation. Taken together, these findings are in line with the earlier evidence indicating that thalamic MD and VM nuclei referred as a thalamic 'nociceptive discriminator' participate not only in the discrimination of somatosensory signals but also in the precise regulation of descending controls (Lei and You, 2013; You et al., 2013). Furthermore, it may be proposed that the 
abnormality in descending control of nociception in PD reflects imbalanced homeostasis of the dopaminergic regulation of the brain, particularly that of the thalamic MD/VM nuclei.

\section{Central dopaminergic system in pain modulation.}

Dopamine has a widespread distribution in the brain (Lindvall and Björklund, 1974; Young and Wilcox, 1991; García-Cabezas et al., 2009). A number of studies have provided convincing evidence that the dopaminergic system of the brain is involved in regulation of nociception. Dopaminergic compounds acting on dopamine D2 rather than D1 receptor have been shown to induce antinociception when administered e.g. into the striatum (Altier and Stewart, 1998; Magnusson and Fisher, 2000). Among brain structures innervated by dopaminergic efferents and expressing dopamine D2 receptors is the thalamus (Bouthenet et al., 1991; Garcia-Cabezas et al., 2009; Young and Wilcox, 1991). This finding provides a plausible explanation for the present results indicating that dopaminergic mechanisms acting on the dopamine D2 receptor in the thalamus are involved in the regulation of descending control of nociception. In accordance with this, administration of dopamine into the thalamic VM/MD nucleus reversed the PD-induced pronociceptive changes in descending control of nociception. Conversely, administration of a selective dopamine D2 receptor antagonist into the thalamic VM nucleus prevented the antinociceptive effects induced by i.m. heating-needle stimulation in PD. The present results suggest that $43^{\circ} \mathrm{C}$ heating-needle stimulation provides a novel therapy for attenuating pain in 
PD that according to current experimental results might be accompanied by attenuation of the early-stage motor symptoms in PD. It is, however, interesting to note that pain modulation might be different in various pain models, i.e. muscle pain versus neuropathic pain (Le Bars et al., 2001). It has also been reported that dopamine D1 receptor may participate in pain facilitation rather than inhibition in spinal and supraspinal structures (Coffeen et al., 2008; Aira et al., 2016). Thus, experiments addressing the role of the subtype of dopamine receptors in descending modulation of various pains in the early stage of PD is required in the future.

\section{CONCLUSION}

The present study is the first to show dysregulation of the equilibrium between the descending inhibitory and facilitatory pain systems in the early-stage of PD, which may contribute to chronification of pain with further development of PD. In addition, the present study raises the possibility that i.m. heating-needle stimulation at a temperature of $43{ }^{\circ} \mathrm{C}$ provides an additional alternative treatment both for the sensory and motor disorder of PD at an early stage of the disease.

\section{Conflict of interest statement}

The authors declare no personal or financial conflicts of interest.

\section{Acknowledgments}


The present work was supported by grants from the National Natural Science Foundation of China (81772451, 81860410), the Academy of Finland (315043), and the Sigrid Jusélius Foundation, Helsinki, Finland.

\section{REFERENCES}

Agid Y, Javoy F, Glowinski J, Bouvet D, Sotelo C (1973) Injection of

6-hydroxydopamine into the substantia nigra of the rat. II. Diffusion and specificity. Brain Res 58:291-301.

Aira Z, Barrenetxea T, Buesa I, Martínez E, Azkue JJ (2016) Spinal D1-like dopamine receptors modulate NMDA receptor-induced hyperexcitability and NR1 subunit phosphorylation at serine 889. Neurosci Lett 618:152-158.

Altier N, Stewart J (1998) Dopamine receptor antagonists in the nucleus accumbens attenuate analgesia induced by ventral tegmental area substance $\mathrm{P}$ or morphine and by nucleus accumbens amphetamine. J Pharmacol Exp Ther 285:208-215.

Beiske AG, Loge JH, Rønningen A, Svensson E (2009) Pain in Parkinson's disease: prevalence and characteristics. Pain 141:173-177.

Berger K, Przedborski S, Cadet JL (1991) Retrograde degeneration of nigrostriatal neurons induced by intrastriatal 6-hydroxydopamine injection in rats. Brain Res Bull 26:301-307.

Bernheimer H, Birkmayer W, Hornykiewicz O, Jellinger K, Seitelberger F (1973) Brain dopamine and the syndromes of Parkinson and Huntington. Clinical, morphological and neurochemical correlations. J Neurol Sci 20:415-455. 
Bethel-Brown CS, Morris JK, Stanford JA (2011) Young and middle-aged rats exhibit isometric forelimb force control deficits in a model of early-stage Parkinson's disease. Behav Brain Res 225:97-103.

Boss R van den, Cools AR, Ogren SO (1988) Differential effects of the selective D2-antagonist raclopride in the nucleus accumbens of the rat on spontaneous and d-amphetamine-induced activity. Psychopharmacology (Berl) 95:447-451.

Bouthenet ML, Souil E, Martres MP, Sokoloff P, Giros B, Schwartz JC (1991) Localization of dopamine D3 receptor mRNA in the rat brain using in situ hybridization histochemistry: comparison with dopamine D2 receptor mRNA. Brain Res 564:203-219.

Breese GR, Cooper BR, Smith RD (1974) Biochemical and behavioural alterations following 6-hydroxydopamine administration into brain. Biochem Pharmacol 23 (suppl 1):574-579.

Buhidma Y, Rukavina K, Chaudhuri KR, Duty S (2020) Potential of animal models for advancing the understanding and treatment of pain in Parkinson's disease. NPJ Parkinsons Dis ;6:1.

Buhmann C, Wrobel N, Grashorn W, Fruendt O, Wesemann K, Diedrich S, Bingel U (2017) Pain in Parkinson's disease: a cross-sectional survey of its prevalence, specifics, and therapy. J Neurol 264:758-769.

Burkey AR, Carstens E, Jasmin L (1999) Dopamine reuptake inhibition in the rostral agranular insular cortex produces antinociception. J Neurosci 19:4169-4179.

Campos ACP, Berzuino MB, Hernandes MS, Fonoff ET, Pagano RL (2019) 
Monoaminergic regulation of nociceptive circuitry in a Parkinson's disease rat model. Exp Neurol 318:12-21.

Chen CCV, Shih YYI, Chang C (2013) Dopaminergic imaging of nonmotor manifestations in a rat model of Parkinson's disease by fMRI. Neurobiol Dis 49:99-106.

Chudler EH, Dong WK (1995) The role of the basal ganglia in nociception and pain. Pain 60:3-38.

Coffeen U, López-Avila A, Ortega-Legaspi JM, Ángel AD, López-Muñoz FJ, Pellicer F (2008) Dopamine receptors in the anterior insular cortex modulate long-term nociception in the rat. Eur J Pain 12:535-543.

Deumens R, Blokland A, Prickaerts J (2002) Modeling Parkinson's disease in rats: an evaluation of 6-OHDA lesions of the Nigrostriatal pathway. Exp Neurol 175:303-317.

Domenici RA, Campos ACP, Maciel ST, Berzuino MB, Hernandes MS, Fonoff ET, Pagano RL (2019) Parkinson's disease and pain: Modulation of nociception circuitry in a rat model of nigrostriatal lesion. Exp Neurol 315:72-81.

Ehringer H, Hornykiewicz O (1960) Distribution of noradrenaline and dopamine (3-hytroxytyramine) in the human brain and their behavior in diseases of the extrapyramidal system. Klin Wochenschr 38:1236-1239.

Fahn S (1988) Parkinsonism. In Cecil's Textbook of Medicine, Wyngaarden JB and Smith LH Jr. eds, publisher: Saunders, Philadelphia pp.2143-2147.

García-Cabezas MA, Martínez-Sánchez P, Sánchez-González MA, Garzón M, 
Cavada C (2009) dopamine innervation in the thalamus: Monkey versus rat. Cereb Cortex 19:424-434.

Grant EL, Leavenworth RS (1972) Statistical Quality Control. McGraw-Hill, pp 764. Haber SN, Calzavara R (2009) The cortico-basal ganglia integrative network: The role of the thalamus. Brain Res Bull 78:69-74.

Hagelberg N, Martikainen IK, Mansikka H, Hinkka S, Någren K, Hietala J, Scheinin H, Pertovaara A (2002). Dopamine D2 receptor binding in the human brain is associated with the response to painful stimulation and pain modulatory capacity. Pain 99:273-279.

Hökfelt T, Ungerstedt U (1973) Specificity of 6-hydroxydopamine induced degeneration of central monoamine neurones: an electron and fluorescence microscopic study with special reference to intracerebral injection on the nigro-striatal dopamine system. Brain Res 60:269-297.

Iancu, R., Mohapel, P., Brundin, P., Paul, G., 2005. Behavioral characterization of a unilateral 6-OHDA-lesion model of Parkinson's disease in mice. Behav. Brain Res. $162,1-10$.

Ishida, Y., Kawai, K., Magata, Y., Abe, H., Yoshimoto, M., Takeda, R., Hashiguchi, H., Mukai, T., Saji, H., 2005. Alteration of striatal $\left[{ }^{11} \mathrm{C}\right]$ raclopride and 6-[ $\left[{ }^{18} \mathrm{~F}\right]$ fluoro-1-3,4-dihydroxyphenylalanine uptake precedes development of methamphetamine-induced rotation following unilateral 6-hydroxydopamine lesions of medialforebrain bundle in rats. Neurosci. Lett. 389, 30-34.

Jackson-Lewis V, Blesa J, Przedborski S (2012) Animal models of Parkinson's 
disease. Parkinsonism Relat Disord 18:183-185.

Jalewa J, Sharma MK, Gengler S, Holscher C (2017) A novel GLP-1/GIP dual receptor agonist protects from 6-OHDA lesion in a rat model of Parkinson's disease. Neuropharmacology 117:238-248.

Kaakkola S, Teräväinen H (1990) Animal models of Parkinsonism. Pharmacol Toxicol 67:95-100.

Kilkenny C, Browne W, Cuthill IC, Emerson M, Altman DG; NC3Rs Reporting Guidelines Working Group (2010) Animal research: reporting in vivo experiments: the ARRIVE guidelines. Br J Pharmacol 160:1577-1579.

Kirik D, Rosenblad C, Bjöklund A (1998) Characterization of behavioral and neurodegenerative changes following partial lesions of the nigrostriatal dopamine system induced by intrastriatal 6-hydroxydopamine in the rat. Exp Neurol $152: 259-277$.

Le Bars D, Gozariu M, Cadden SW (2001) Animal Models of Nociception. Pharmacol Rev 53:597-652.

Lei J, You HJ (2013) Endogenous descending facilitation and inhibition differ in control of formalin intramuscularly induced persistent muscle nociception. Exp Neurol 248:100-111.

Lei J, Jin L, Zhao Y, Sui MY, Huang L, Tan YX, Chen YK, You HJ (2011) Sex-related differences in descending norepinephrine and serotonin controls of spinal withdrawal reflex during intramuscular saline induced muscle nociception in rats. Exp Neurol 228:206-214.

Lei J, Pertovaara A, You HJ (2015) Effect of simulated weightlessness on intramuscular hypertonic saline induced muscle pain and spinal Fos expression in rats. Brain Res 1594:204-214. 
Lei J, Ye G, Wu JT, Pertovaara A, You HJ (2017) Role of capsaicin-and heat-sensitive afferents in stimulation of acupoint-induced pain and analgesia in humans. Neuroscience 358:325-335.

Lei J, Ye G, Pertovaara A, You HJ (2020) Effects of intramuscular heating-needle stimulation in controlling adjuvant-induced muscle nociception in rats: differential roles of thalamic purinergic P2X3 receptors. Neuroscience 433:81-93.

Leikas, J.V., Kääriäinen, T.M., Jalkanen, A.J., Lehtonen, M., Rantamäki, T., Forsberg, M.M., 2017. Combined ipsilateral limb use score as an index of motor deficits and neurorestoration in parkinsonian rats. J. Neurosci. Res. 95, 1858-1870.

Lindvall O, Björklund A (1974) The organization of the ascending catecholamine neuron systems in the rat brain as revealed by the glyoxylic acid fluorescence method. Acta Physiol Scand [Suppl] 412:1-48.

Magnusson JE, Fisher K (2000) The involvement of dopamine in nociception: the role of $\mathrm{D}_{1}$ and $\mathrm{D}_{2}$ receptors in the dorsolateral striatum. Brain Res. 855, 260-266.

Kilkenny C, Browne WJ, Cuthill IC, Emerson M, Altman DG (2010) Improving Bioscience Research Reporting: The ARRIVE Guidelines for Reporting Animal Research. PLOS Biol. 8, e1000412.

Miyanishia K, Choudhurya ME, Watanabea M, Kubob M, Nomotob M, Yanoa H, Tanakaa J (2019) Behavioral tests predicting striatal dopamine level in a rat hemi-Parkinson's disease model. Neurochem Int 122:38-46.

Mokry J (1995) Experimental models and behavioural tests used in the study of Parkinson's disease. Physiol Res 44:143-150. 
Obeso JA, Rodriguez-Oroz M, Martin C, Alonso F, Zamarbide I, Lanciego JL, Rodriguez-Diaz M (2004) The origin of motor fluctuations in Parkinson's disease: importance of dopaminergic innervation and basal ganglia circuits. Neurology $62: 17-30$.

Polli A, Weis L, Biundo R, Thacker M, Turolla A, Koutsikos K, Chaudhuri KR, Antonini, A (2016) Anatomical and functional correlates of persistent pain in Parkinson's disease. Mov Disord 31:1854-1864.

Przedborski S, Levivier M, Jiang H, Ferreira M, Jackson-Lewis V, Donaldson D, Togasaki DM (1995). Dose dependent lesions of the dopaminergic nigrostriatal pathway induced by intrastriatal injection of 6-hydroxydopamine. Neuroscience 67:631-647.

Sauer H, Oertel WH (1994) Progressive degeneration of nigrostriatal dopamine neurons following intrastriatal terminal lesions with 6-hydroxydopamine: A combined retrograde tracing and immunocytochemical study in the rat. Neuroscience 59:401-415.

Schapira AHV, Chaudhuri KR, Jenner P (2017) Non-motor features of Parkinson disease. Nat Rev Neurosci 18:435-450

Senoh S, Creveling CR, Udenfriend S, Witkop B (1959) Chemical, enzymatic and metabolic studies on the mechanism of oxidation of dopamine. J Am Chem Soc $81: 6236-6240$.

Senoh S, Witkop B (1959) Non enzymatic conversions of dopamine to norepinephrine and trihydroxyphenethylamine. J Am Chem Soc 81:6222-6231. 
Takeda R, Ishida Y, Ebihara K, Abe H, Matsuo H, Ikeda T, Koganemaru G, Kuramashi A, Funahashi H, Magata Y, Kawai K, Nishimori T (2014) Intrastriatal grafts of fetal ventral mesencephalon improve allodynia-like withdrawal response to mechanical stimulation in a rat model of Parkinson's disease. Neurosci Lett 573:19-23.

Tong Q, Zhang L, Yuan YS, Jiang SM, Zhang R, Xu QR, Ding J, Li DQ, Zhou XB, Zhang KZ (2015) Reduced plasma serotonin and 5-hydroxyindoleacetic acid levels in Parkinson's disease are associated with nonmotor symptoms. Parkinsonism Relat Disord 21:882-887.

Wasner G, Deuschl G (2012) Pains in Parkinson disease-many syndromes under one umbrella. Nat Rev Neurol 8:284-294.

Wood PB (2008) Role of central dopamine in pain and analgesia. Expert Rev Neurother 8:781-797.

Xiao Y, Lei J, Ye G, Xu H, You HJ (2015) Role of thalamic nuclei in modulation of Fos expression within cerebral cortex during hypertonic saline induced muscle nociception. Neuroscience 304, 36-46.

You HJ, Lei J, Sui MY, Huang L, Tan YX, Tjølsen A, Arendt-Nielsen L (2010) Endogenous descending modulation: spatiotemporal effect of dynamic imbalance between descending facilitation and inhibition of nociception. J Physiol $588: 4177-4188$

You HJ, Lei J, Niu N, Yang L, Fan XL, Tjølsen A, Li Q (2013) Specific thalamic nuclei function as novel 'nociceptive discriminators' in the endogenous control of nociception in rats. Neuroscience 232:53-63. 
MS. no.: NSC-20-0304

You HJ, Lei J, Ye G, Fan XL, Li Q (2014) Influence of intramuscular heat stimulation on modulation of nociception: complex role of central opioid receptors in descending facilitation and inhibition. J Physiol 592:4365-4380.

You HJ, Lei J, Xiao Y, Ye G, Sun ZH, Yang L, Niu N (2016) Pre-emptive analgesia and its supraspinal mechanisms: enhanced descending inhibition and decreased descending facilitation by dexmedetomidine. J Physiol 594:1875-1890.

Young KA, Wilcox RE (1991) Characterization of D2 receptors and dopamine levels in the thalamus of the rat. Life Sci 48:1845-1852.

Yuan H, Sarre S, Ebinger G, Michotte Y (2005) Histological, behavioural and neurochemical evaluation of medial forebrain bundle and striatal 6-OHDA lesions as rat models of Parkinson's disease. J Neurosci Methods 144:35-45.

Zengin-Toktas Y, Ferrier J, Durif F, Llorca PM, Authier N (2013) Bilateral lesions of the nigrostriatal pathways are associated with chronic mechanical pain hypersensitivity in rats. Neurosci Res 76:261-264. 


\section{Legends to figures}

Fig. 1. Diagram of the experimental design showing variations of spinally-organized nociception assessed by bilateral measurements of hind paw withdrawal reflexes elicited by noxious mechanical and heat stimuli in different experimental conditions. Solid dark areas on the heel part of the bilateral hind paws represent the stimulation site of mechanical (mech.) and heat stimuli. In the naive rat group, paw withdrawal reflexes in response to intramuscular (i.m.) injection of $5.8 \%$ or $0.9 \%$ saline into the gastrocnemius (GS) muscle (m.), followed by i.m. heating-needle stimulation (H.N.S.) at the temperature of $43^{\circ} \mathrm{C}$, were observed for 7 days. Responses of naive rats treated by intracerebral (i.c.) administration of dopamine into the striatum were investigated for $4 \mathrm{~h}$ for the determination of potential effects of dopamine in the physiological state. In the striatal vehicle-treatment group, behavior was observed for 3 weeks after the striatal administration of vehicle, after which the animals were given i.m. injection of $5.8 \%$ or $0.9 \%$ saline followed by a behavioral observation period lasting one week. In the striatal 6-OHDA-treatment group, behavior was observed for 3 weeks after unilateral i.c. lesion of the striatum with 6-OHDA, after which the animals were given i.m. injection of $5.8 \%$ or $0.9 \%$ saline that was followed by 1 week observation period, during which the rats were treated with either needle stimulation (N.S.) or H.N.S. at the temperature of $43^{\circ} \mathrm{C}$ followed by i.c. application of $0.9 \%$ saline, dopamine, or raclopride into the thalamic mediodorsal (MD) or (VM) nuclei, or the striatum. For evaluation of motor dysfunction, Rota-rod test and the 
apomorphine-induced asymmetric rotation behavior were assessed in all experimental groups. $\mathrm{W}=$ week, $\mathrm{d}=$ day, $\mathrm{h}=$ hour, $\mathrm{hp}=$ hours after i.c. treatment

Fig. 2. Withdrawal reflex responses evoked by noxious mechanical and heat stimulation of the hind paw prior to and $21 \mathrm{~d}$ post the unilateral lesion of striatum with either 6-OHDA or vehicle ( $0.9 \%$ saline with $0.2 \%$ ascorbic acid). Neither mechanical paw withdrawal threshold (a - ipsilateral to the lesion and b - contralateral to the lesion) nor paw withdrawal latency to heat (c - ipsilateral to the lesion and d contralateral to the lesion) was influenced in the 6-OHDA-lesioned rats compared with the vehicle-treated rats and naive rats (control). (Control group: naive rats without receiving any treatments; B: baseline response before the lesion) ( $\mathrm{n}=10$ for each group)

Fig. 3. Mechanically ( $\mathrm{a}$ - ipsilateral to the lesion and b - contralateral to the lesion) and heat (c - ipsilateral to the lesion and $\mathrm{d}$ - contralateral to the lesion) evoked paw withdrawal responses in 6-OHDA-lesioned rats prior to and post the unilateral i.m. injection with either $0.9 \%$ saline or $5.8 \%$ saline into the GS muscle. Significant mechanical hyperalgesia was found in 6-OHDA- treated rats during the exposure to the i.m. injection of either $0.9 \%$ saline or $5.8 \%$ saline. In contrast to the prolonged paw withdrawal thermal latency (heat hypoalgesia) in vehicle treated rats, no significant difference in heat-evoked responses was found in 6-OHDA treated rats. * $P<0.05$ and $\# P<0.05$ compared with rats treated only by the i.m. injection with 
$0.9 \%$ saline or $5.8 \%$ saline. (Control: naive rats without receiving any treatments; B: baseline response before the striatal 6-OHDA lesion; B1: baseline response before the i.m. injection of $0.9 \%$ saline or $5.8 \%$ saline $)(n=10$ for each group)

Fig. 4. Effects of intracerebral (i.c.) administration of $5 \mu \mathrm{g}$ of dopamine into the striatum in 6-OHDA-treated rats or naive rats that also received unilaterally intramuscular (i.m.) injection of $5.8 \%$ saline to induce conditioning muscle nociception (Mechanical responses: $\mathrm{a}$ - ipsilateral to the lesion and $\mathrm{b}$ - contralateral to the lesion; heat responses: $\mathrm{c}$ - ipsilateral to the lesion and d - contralateral to the lesion). No significant differences were found among groups received different treatments (B: baseline response before the i.c. administration of 6-OHDA; B1: baseline response before the i.m. injection of $5.8 \%$ saline) ( $n=10$ for each group).

Fig. 5. Effects of intracerebral (i.c.) administration of $5 \mu \mathrm{g}$ of dopamine into the thalamic MD nucleus in 6-OHDA-treated rats or naive rats that also received unilaterally intramuscular (i.m.) injection of $5.8 \%$ saline to induce conditioning muscle nociception. Mechanical hyperalgesia ( $\mathrm{a}$ - ipsilateral to the lesion and b contralateral to the lesion) was decreased after i.c. administration of dopamine into the thalamic MD nucleus, whereas no effects of dopamine on heat-evoked responses were found (c - ipsilateral to the lesion and d - contralateral to the lesion). (B: baseline response before the i.c. administration of 6-OHDA; B1: baseline response before the i.m. injection of $5.8 \%$ saline $)(n=10$ for each group). 
Fig. 6. Effects of intracerebral (i.c.) administration of $5 \mu \mathrm{g}$ of dopamine into the thalamic VM nucleus in 6-OHDA-treated rats or naive rats that also received unilaterally intramuscular (i.m.) injection of $5.8 \%$ saline to induce conditioning muscle nociception. Heat hypoalgesia ( $\mathrm{c}$ - ipsilateral to the lesion and d - contralateral to the lesion) from the tested paw was enhanced after i.c. administration of dopamine into the thalamic VM nucleus, whereas no effects of dopamine on mechanically-evoked responses were found ( $\mathrm{a}$ - ipsilateral to the lesion and $\mathrm{b}$ contralateral to the lesion). (B: baseline response before the i.c. administration of 6-OHDA; B1: baseline response before the i.m. injection of $5.8 \%$ saline) $(\mathrm{n}=10$ for each group)

Fig. 7. Effects of ipsilateral heating-needle stimulation at temperature of $43^{\circ} \mathrm{C}$ on mechanically ( $\mathrm{a}$ - ipsilateral to the lesion and $\mathrm{b}$ - contralateral to the lesion) and heat (c - ipsilateral to the lesion and d - contralateral to the lesion) evoked paw withdrawal reflex responses in the 6-OHDA- treated rats. No significant effects of the heating-needle stimulation on mechanically evoked withdrawal reflexes was found. In contrast, bilateral heat hypoalgesia was found following a period of 30-45 min, but not 15 min, of ipsilateral i.m. heating-needle stimulation. $* P<0.05$ compared with the 6-OHDA-treated rats receiving the 45 min needle insertion alone without heating. (B: baseline response before the intracerebral (i.c.) 6-OHDA treatment; B1: baseline response before the heating-needle stimulation or needle-stimulation without heating) ( $\mathrm{n}=10$ for each group). 
Fig. 8. Effect of i.m. heating-needle stimulation at the temperature of $43{ }^{\circ} \mathrm{C}$ for 30 min on mechanically (a - ipsilateral to the lesion and b - contralateral to the lesion) and heat (c - ipsilateral to the lesion and d - contralateral to the lesion) evoked paw withdrawal reflex responses in the intracerebral (i.c.) 6-OHDA-treated rats or naive rats that also received i.m. injection of $5.8 \%$ saline to induce conditioning muscle nociception. In contrast to the failure to influence mechanical hyperalgesia, $43{ }^{\circ} \mathrm{C}$ heating-needle stimulation enhanced and induced heat hypoalgesia in naive rats and 6-OHDA-treated rats that had received intramuscular (i.m.) injection of 5.8\% saline to induce conditioning muscle nociception. ${ }^{*} P<0.05$ compared with the naive rats receiving the i.m. heating-needle stimulation. (B: baseline response before the i.c. administration of 6-OHDA; B1: baseline response before the i.m. injection of $5.8 \%$ saline; H.N.S.: heating-needle stimulation) $(\mathrm{n}=10$ for each group)

Fig. 9. Effects of intracerebal (i.c.) microinjection with different doses of 0.1-2.5 $\mu \mathrm{g} / 0.5 \mu \mathrm{l}$ raclopride into the contralateral thalamic VM nucleus on the heating-needle stimulation elicited heat hypoalgesia in the 6-OHDA treated rats. The intramuscular (i.m.) heating-needle stimulation induced heat hypoalgesia was significantly depressed by raclopride in a dose-depend manner (a - ipsilateral to the lesion and $\mathrm{b}$ - contralateral to the lesion). ${ }^{*} P<0.05$ compared with the 6-OHDA treated rats receiving the i.c. treatment with $0.9 \%$ saline. (B: baseline response before the i.c. 6-OHDA; B1: baseline response before the i.m. injection of $5.8 \%$ saline; H.N.S.: heating-needle stimulation) $(\mathrm{n}=10$ for each group) 
Fig. 10. Reconstructions of the locations of 210 chemical lesions of striatum with 6-OHDA (panel 'a'), 20 microinjection sites of dopamine within the striatum (panel 'b'), and of 50 microinjection sites of dopamine and raclopride $(0.1 / 0.5 / 2.5 \mu \mathrm{g})$ within the thalamic mediodorsal (MD) and ventromedial (VM) nuclei (panel 'c'). The spread regions of lesion and microinjection are marked by gray areas. Effective sites for 6-OHDA and vehicle ( $0.9 \%$ saline) lesion are indicated by diamonds and up-triangles in panel 'a'. Microinjection sites of dopamine and $0.9 \%$ saline are indicated by down-triangles and up-triangles in panel 'b'. Microinjection sites of dopamine and vehicle within MD and VM nuclei are indicated by down-triangles and up-triangles. Different doses of $0.1 / 0.5 / 2.5 \mu \mathrm{g}$ of raclopride and $0.9 \%$ saline within VM nucleus are indicated by circles, squares, diamonds, and up-triangles in panel 'c', respectively. Please note that some microinjection sites overlap with others in this reconstructions drawing. 


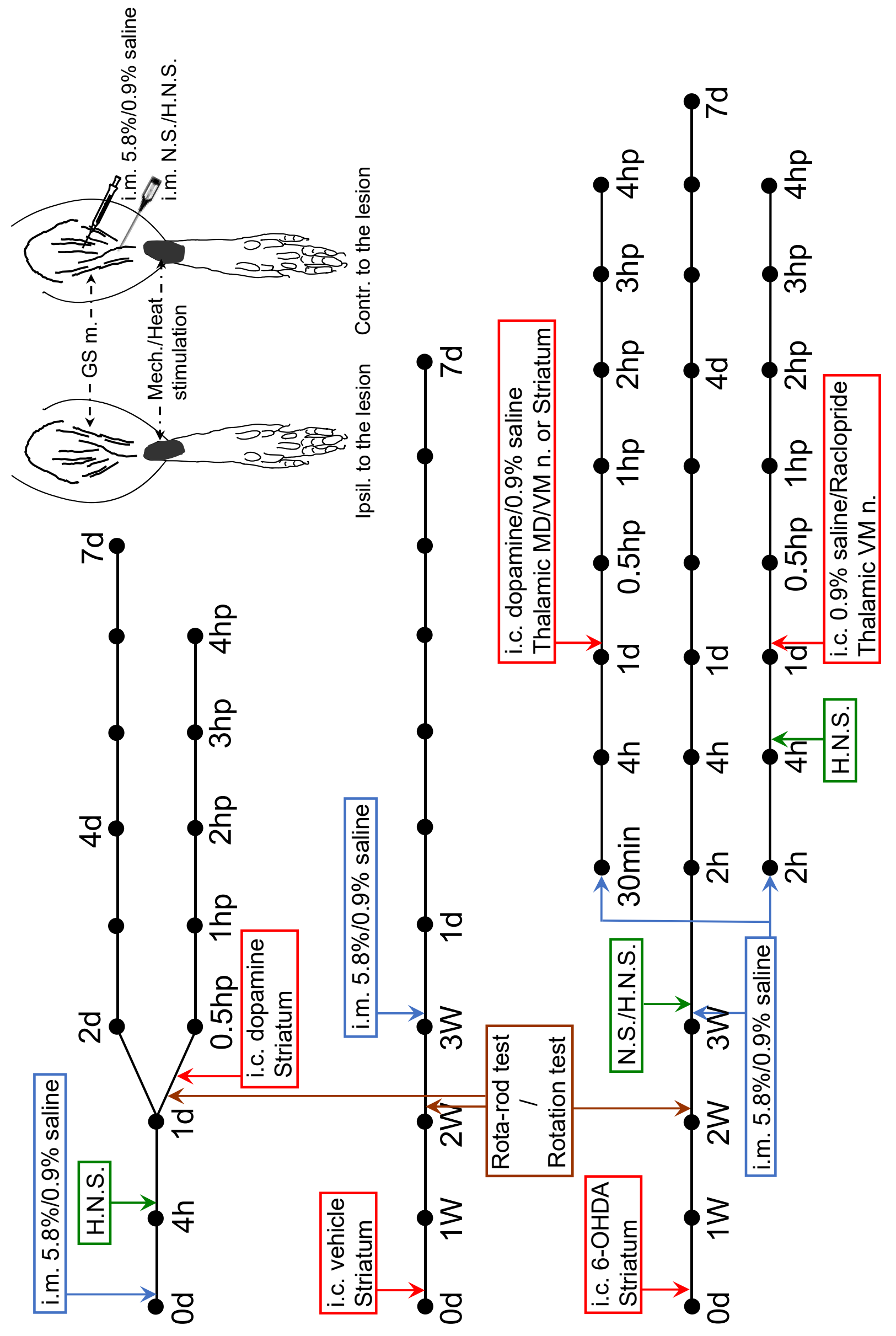

$\frac{\infty}{2} \frac{\infty}{\pi}$

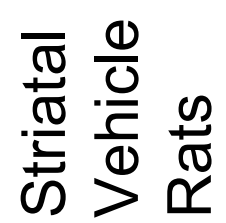

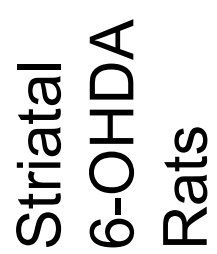




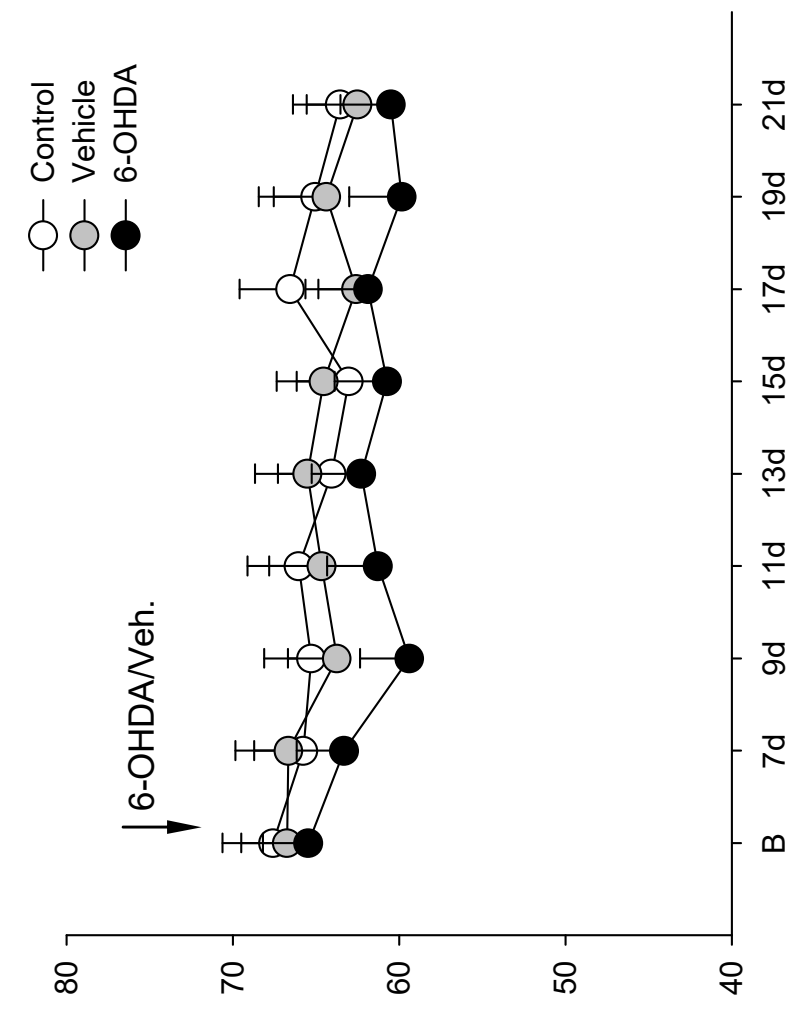

$m$

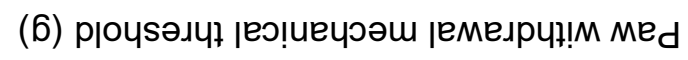

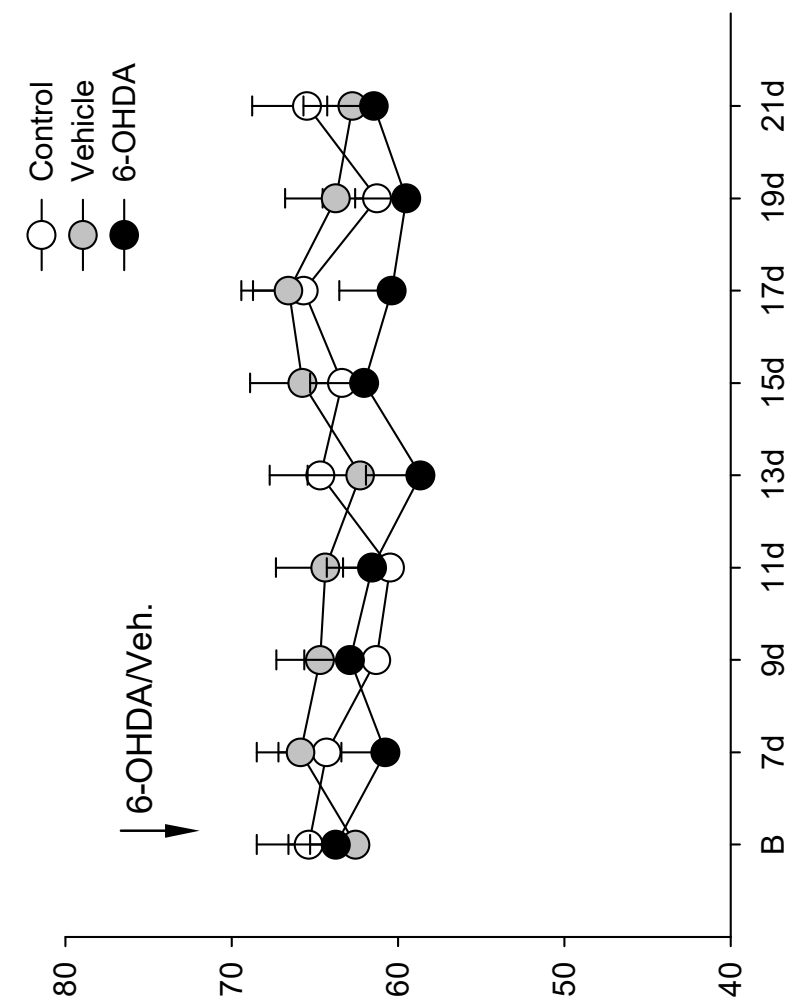

$\varangle$

(6) руочsәлчң јео!иечәәш јемелрцұ!м меd

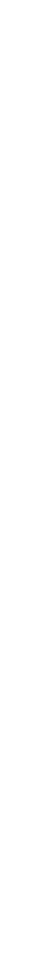

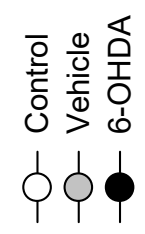

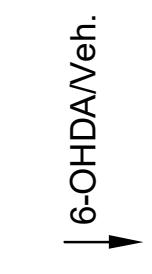

$\stackrel{0}{\circ}$

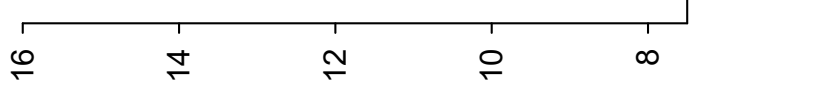

(эәs) Кэиәңе ешиәчұ јемелрч!!м мед

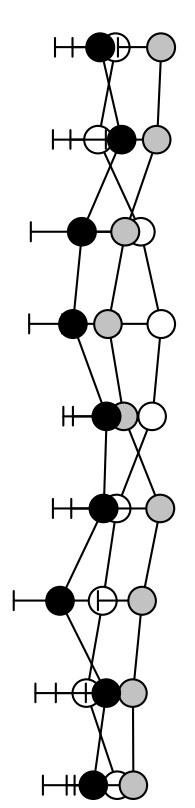

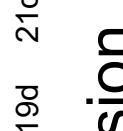

$\therefore \underline{0}$

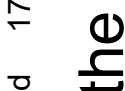

$\stackrel{2}{\rightarrow}$

宛

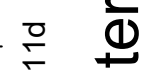

$\therefore \frac{\pi}{\pi}$

$\therefore$ ठั

$\infty$
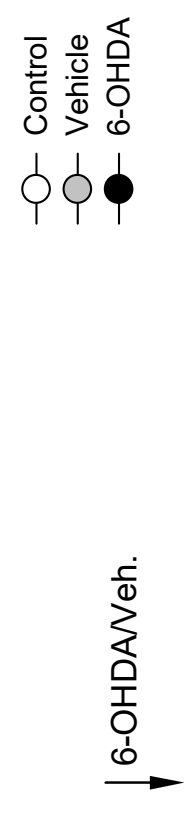


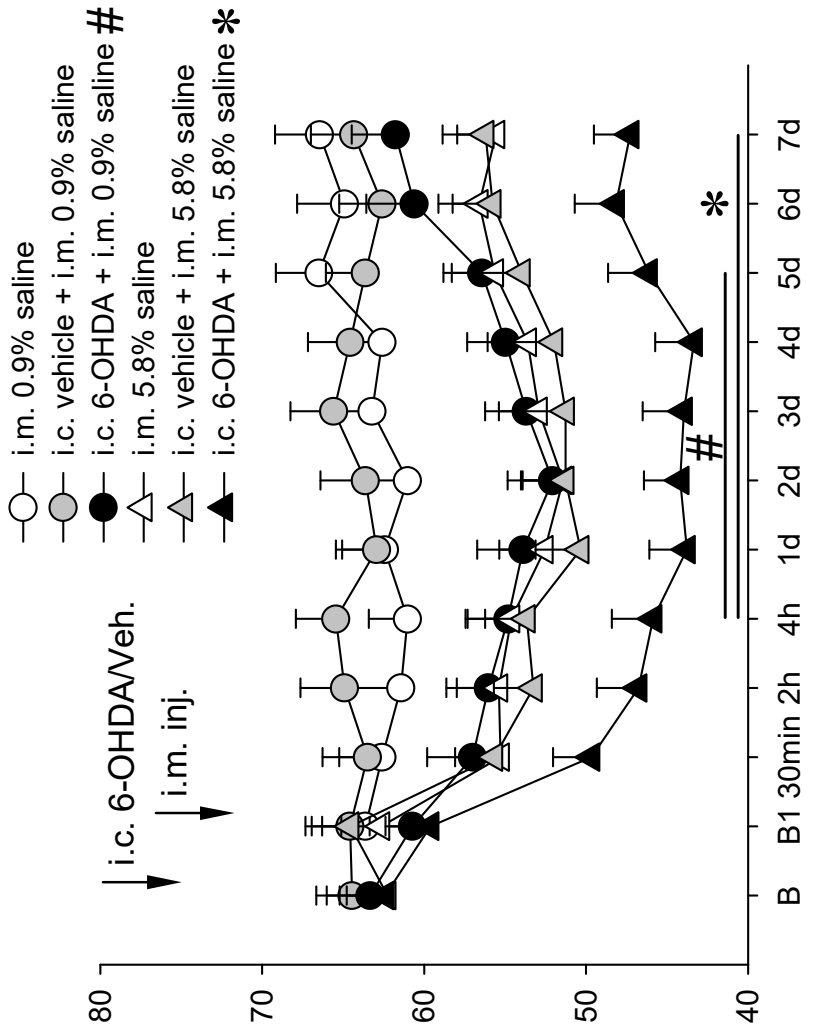

a

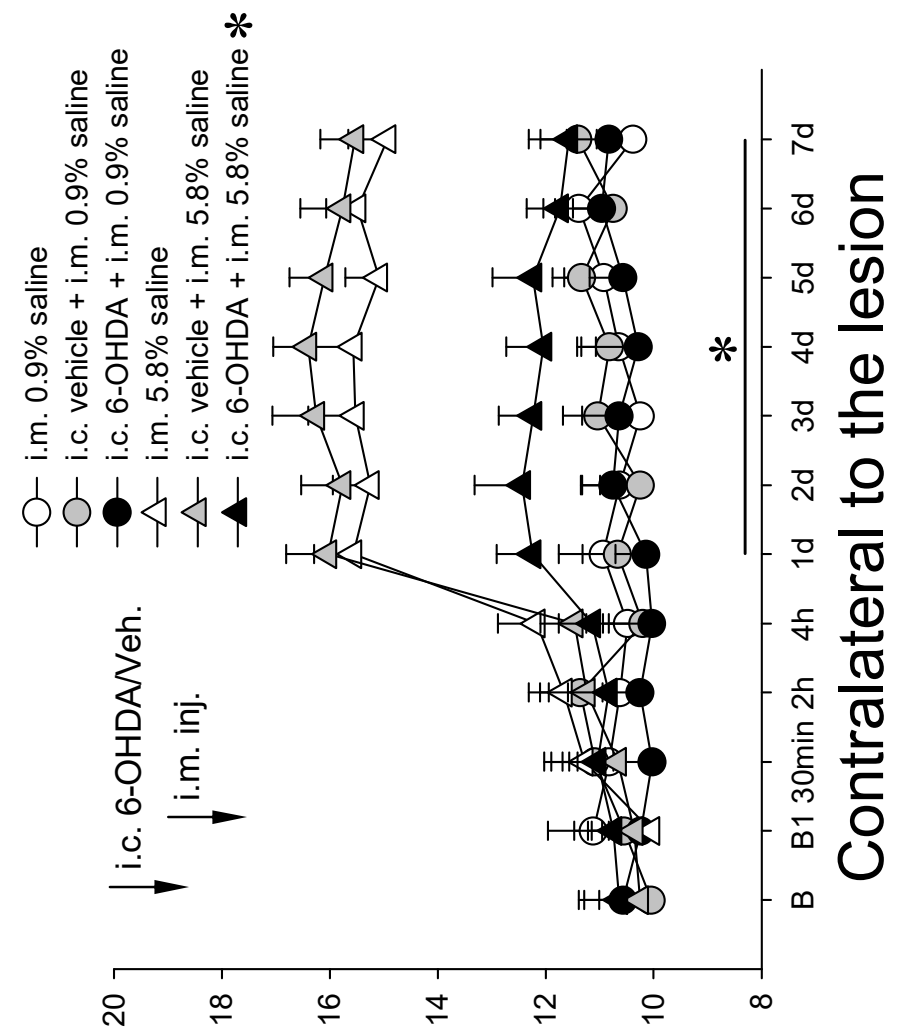

(วәs) Коиәје| јешләцұ јемелрцұ!м мед

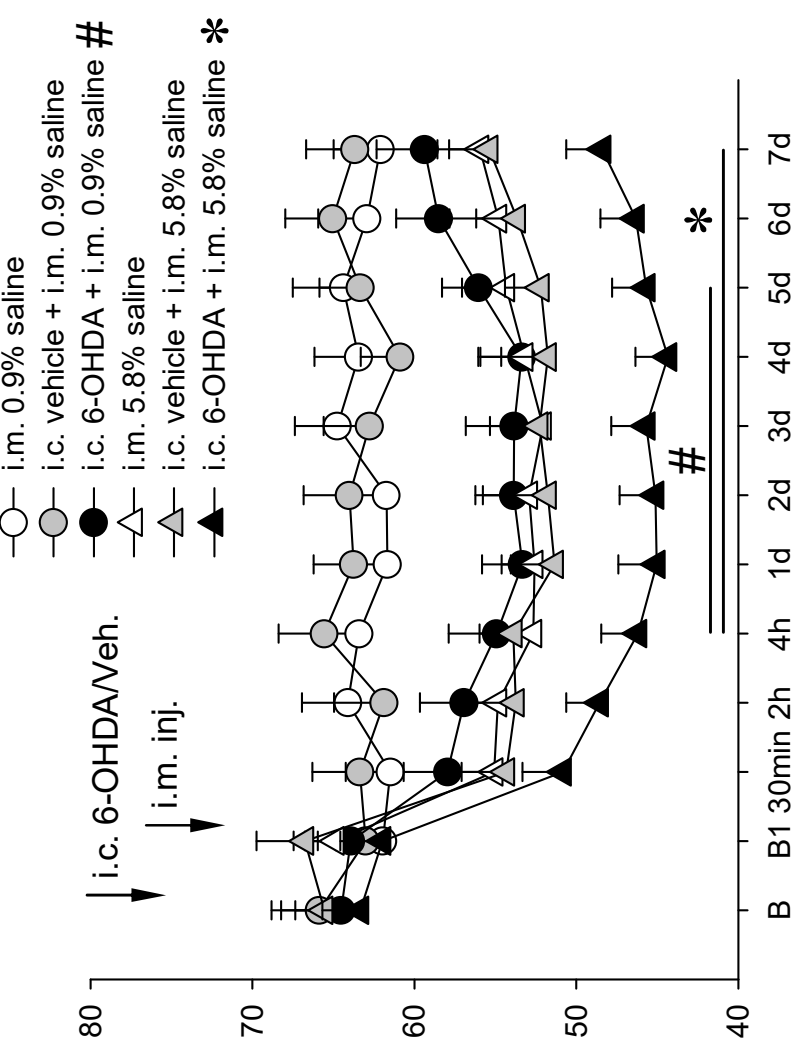

$\varangle \quad$ (6) рІочsәдчұ ןер!иецәәш јемедрц!!м мед

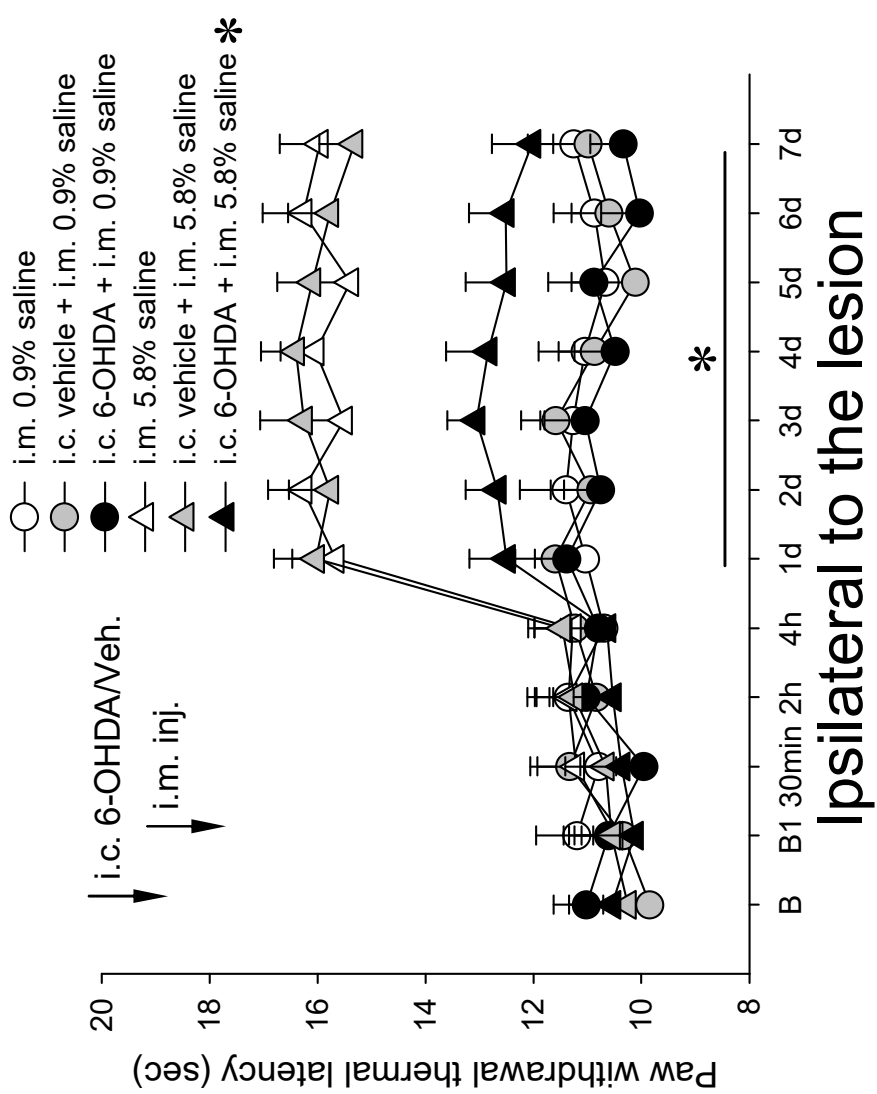




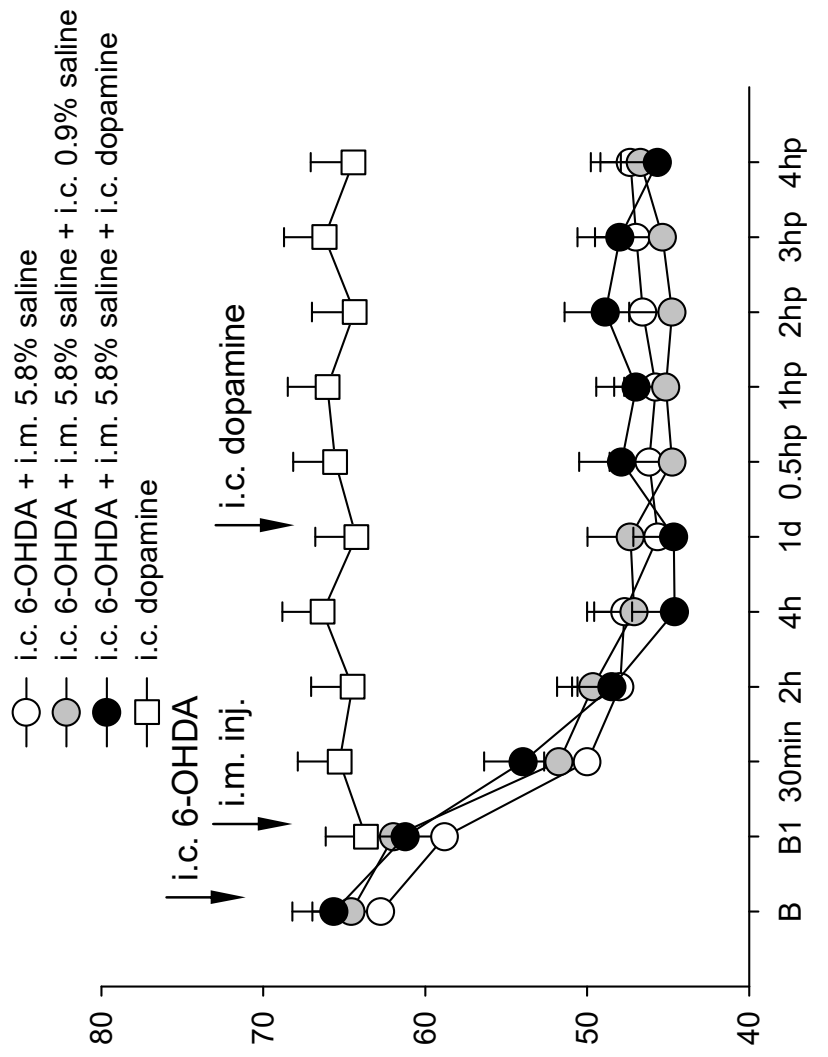

$m$

(6) рјочsәлчұ јеэ!иечәәш јемелрцұ!м мед
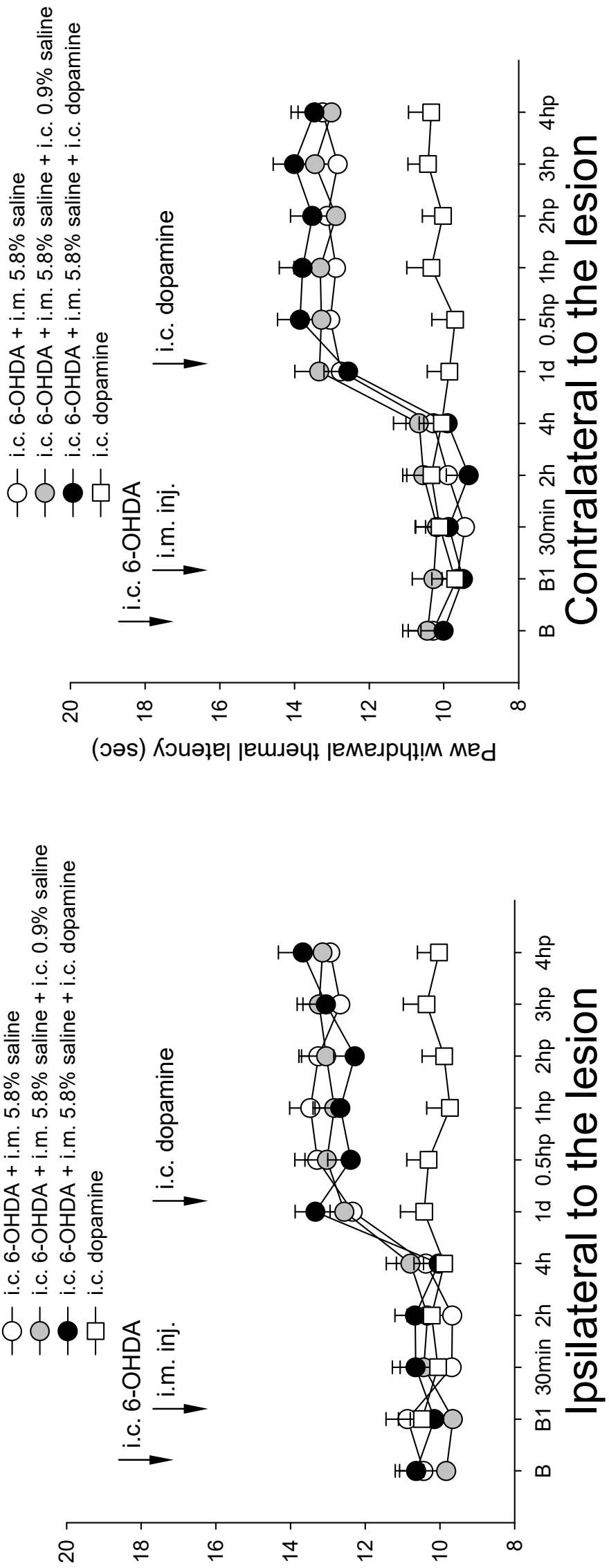

(оәs) Коиәје| јешләцұ јемелрцұ!м мед 


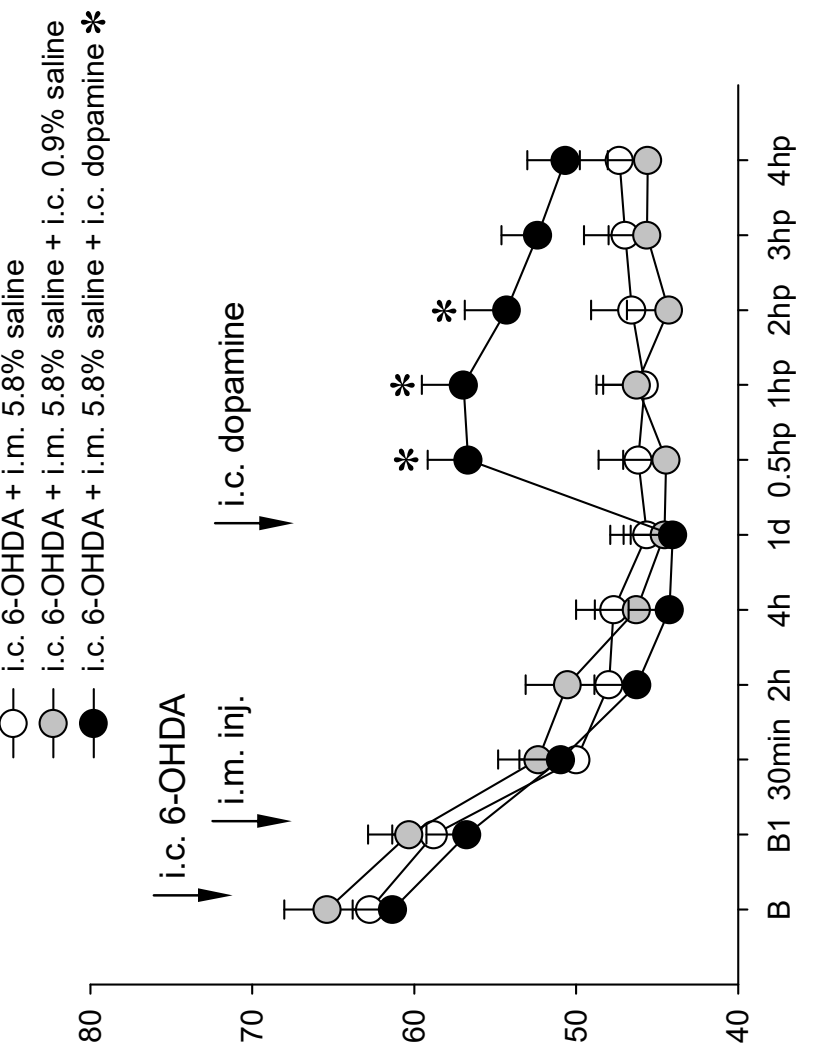

$m$

(6) роочsәцчұ ןеэ!иецәәш јемедрц!!м мед

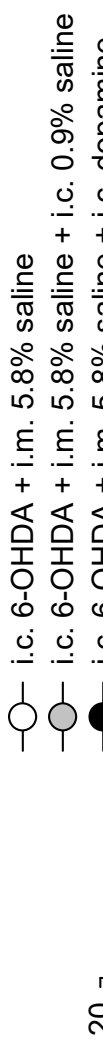

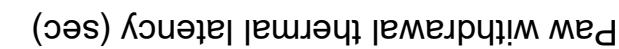

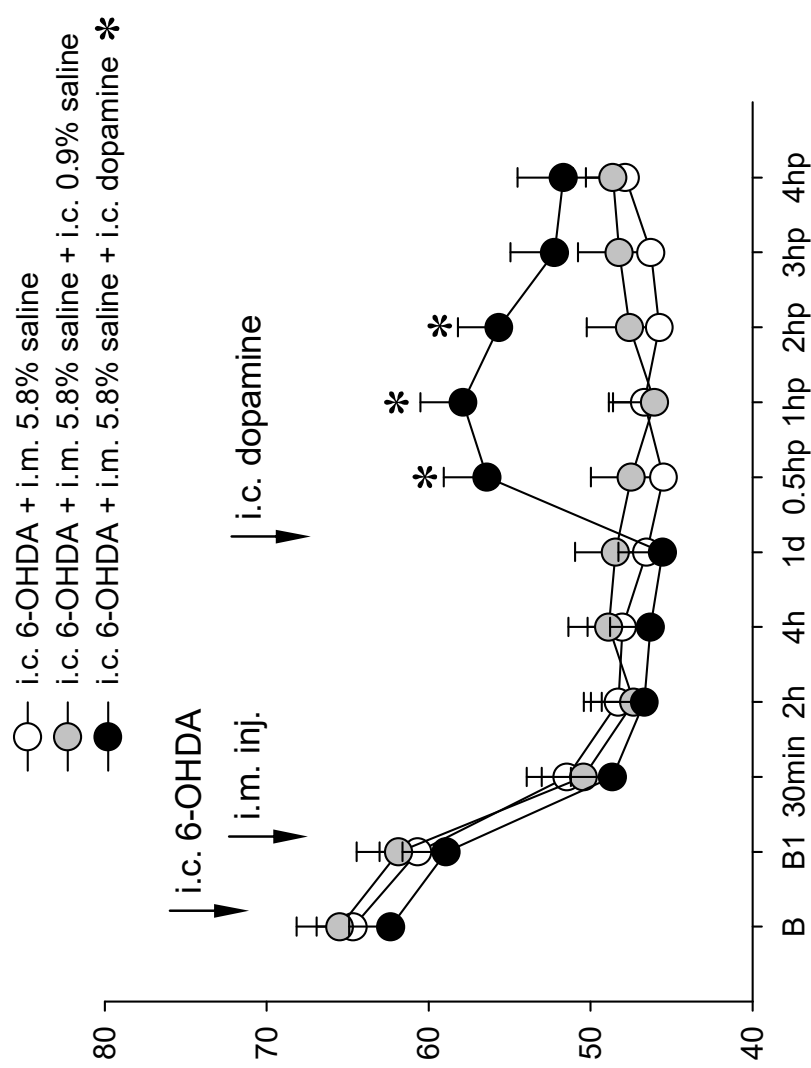

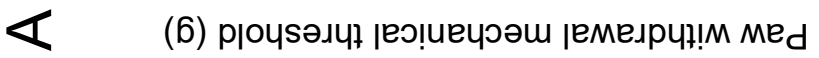

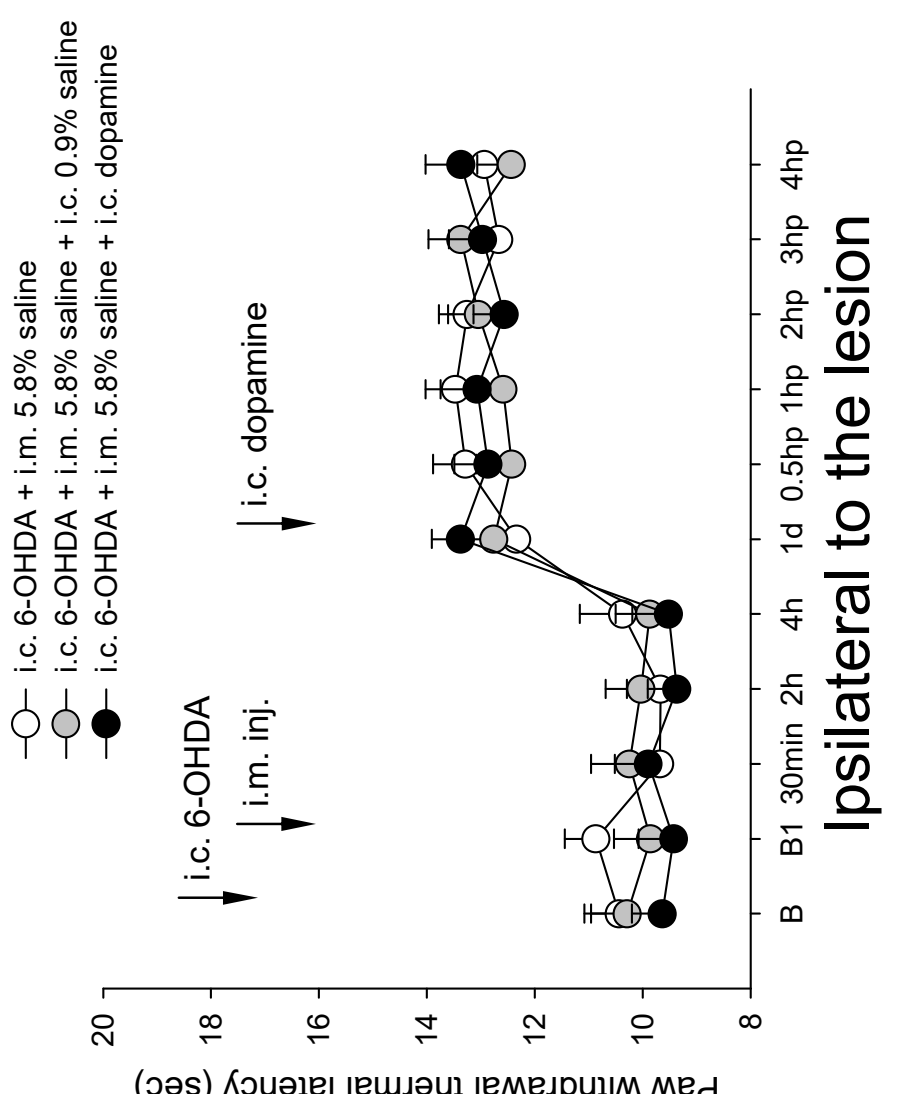

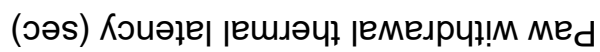




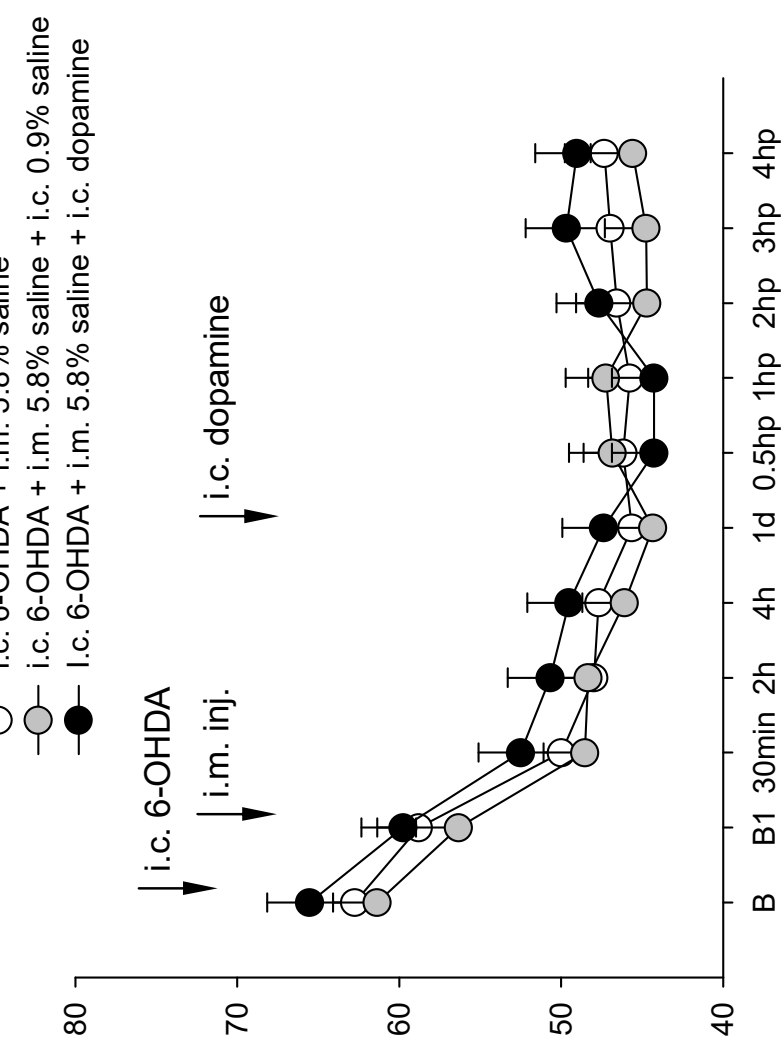

$m$

(6) роочьәдчұ ןеэ!иецәәш јемедрц!!м мед

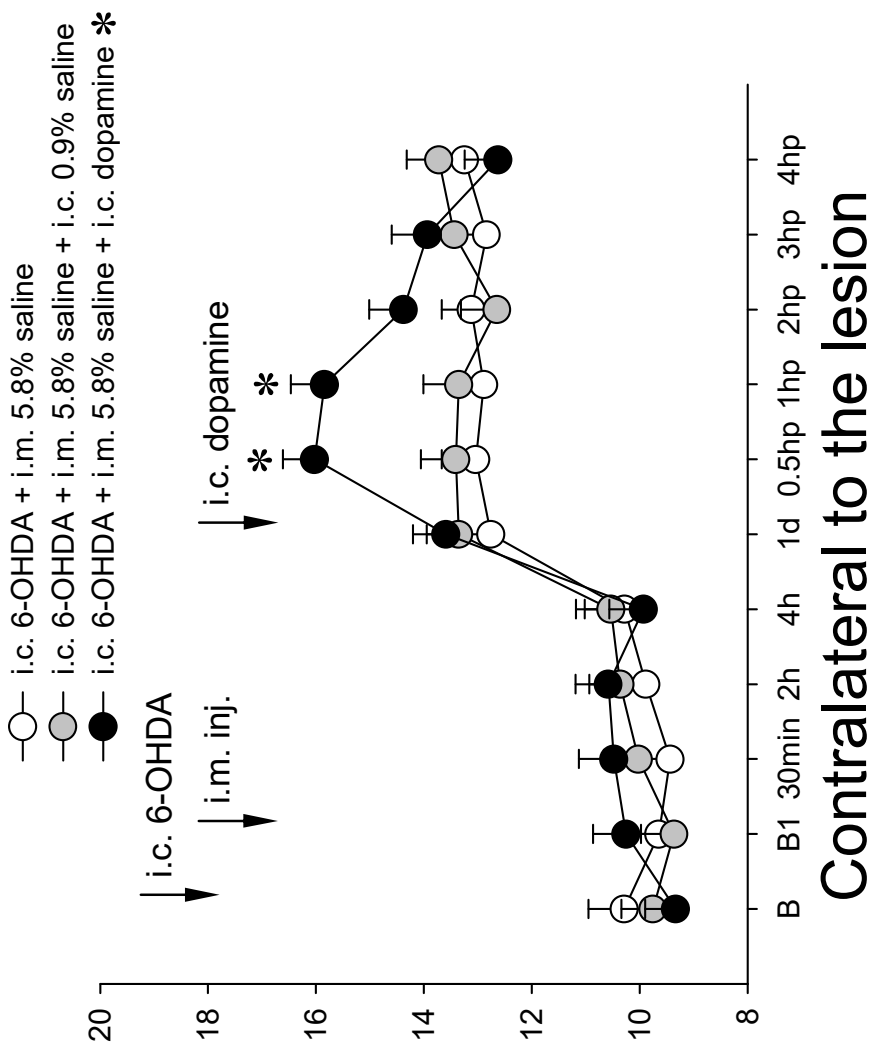

(әәs) Кэиәје| ןешләчұ ןемецрцұ!м мед

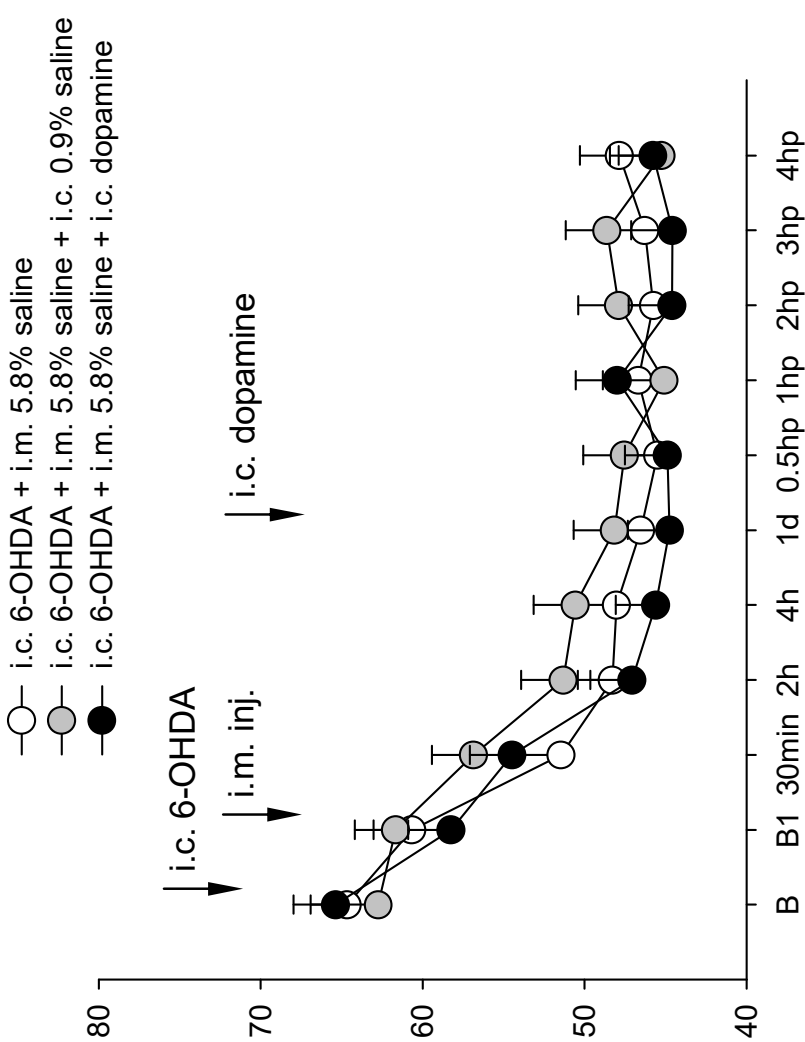

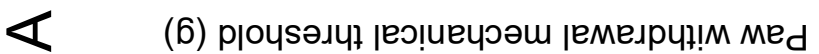

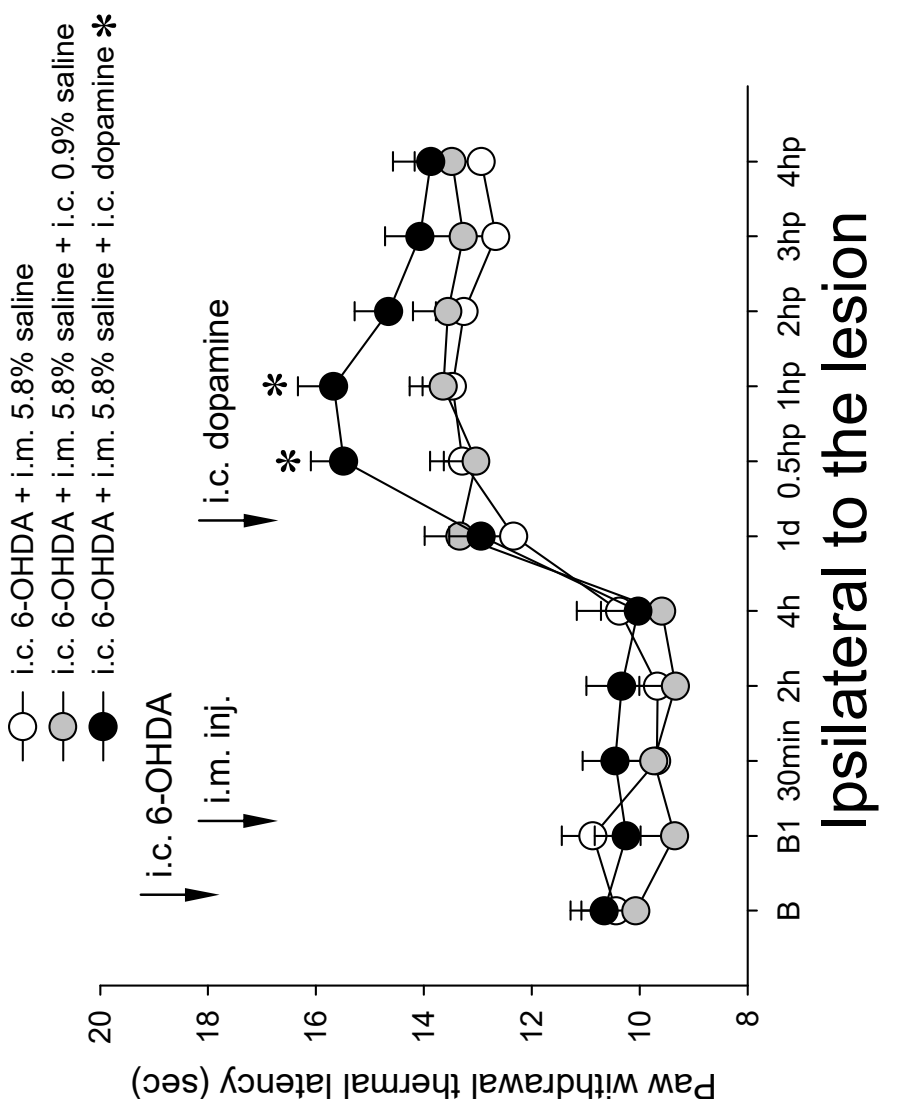




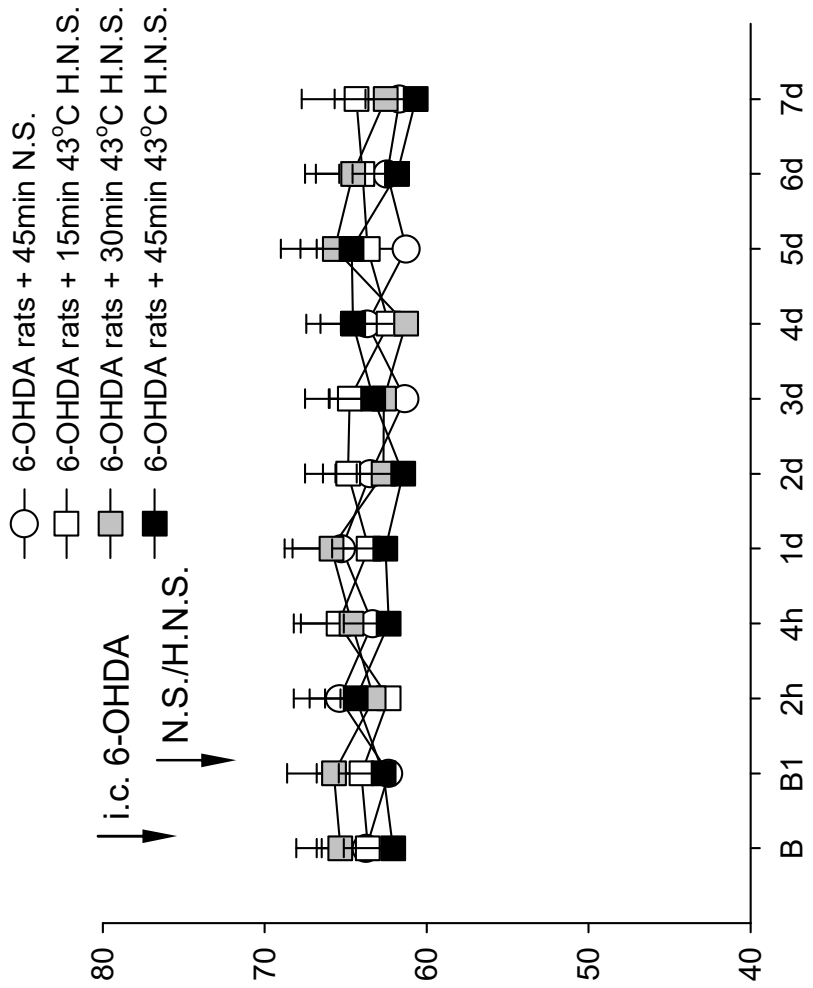

$m$

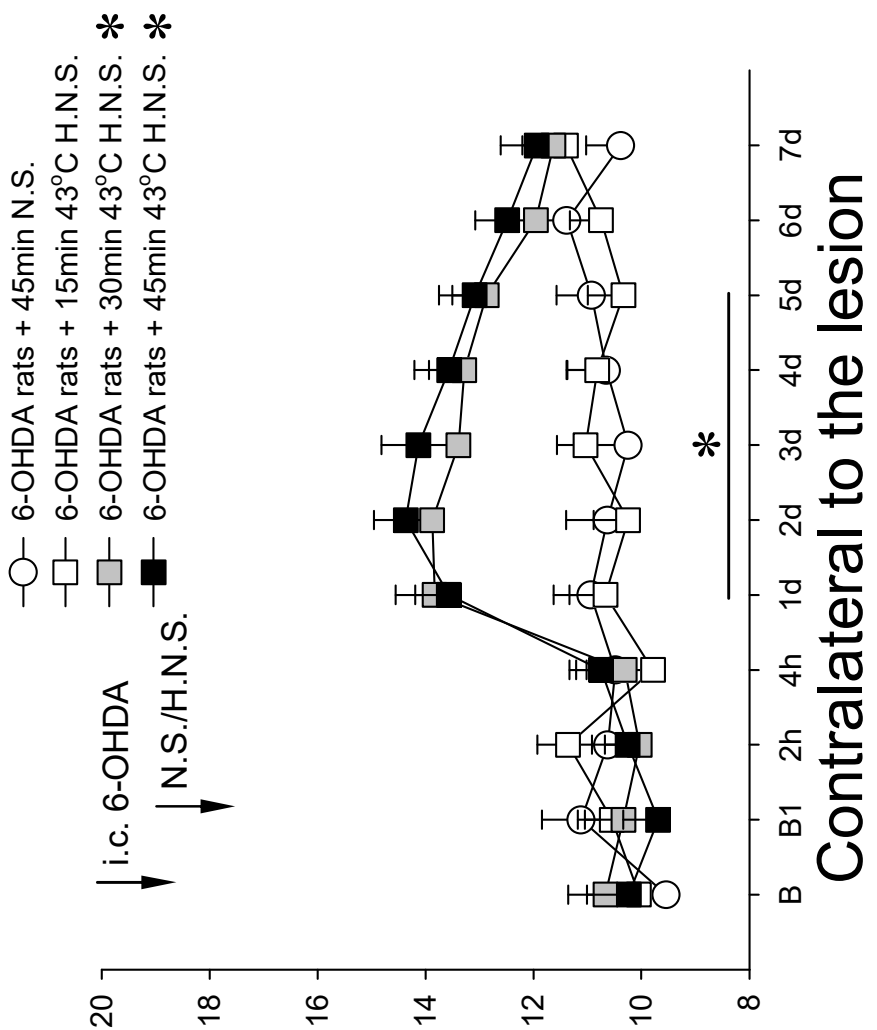

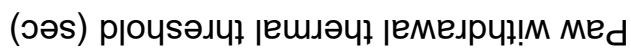

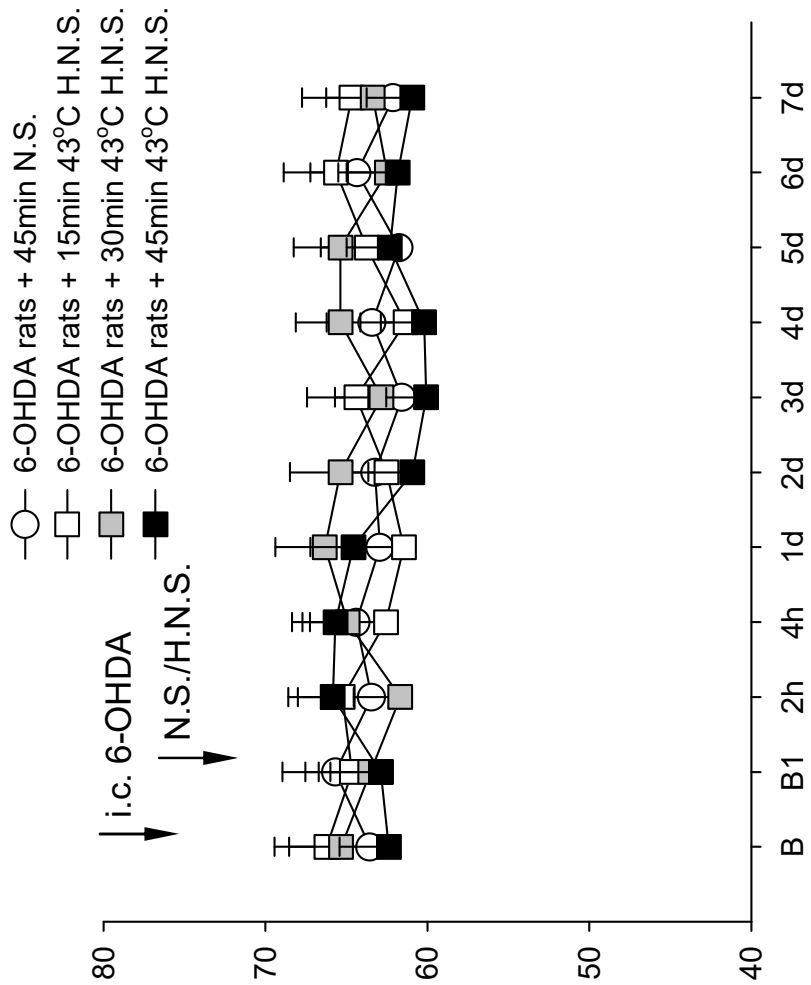

$\varangle \quad$ (6) ріочsәлчұ јео!иецәәш јемелрцұ!м мед

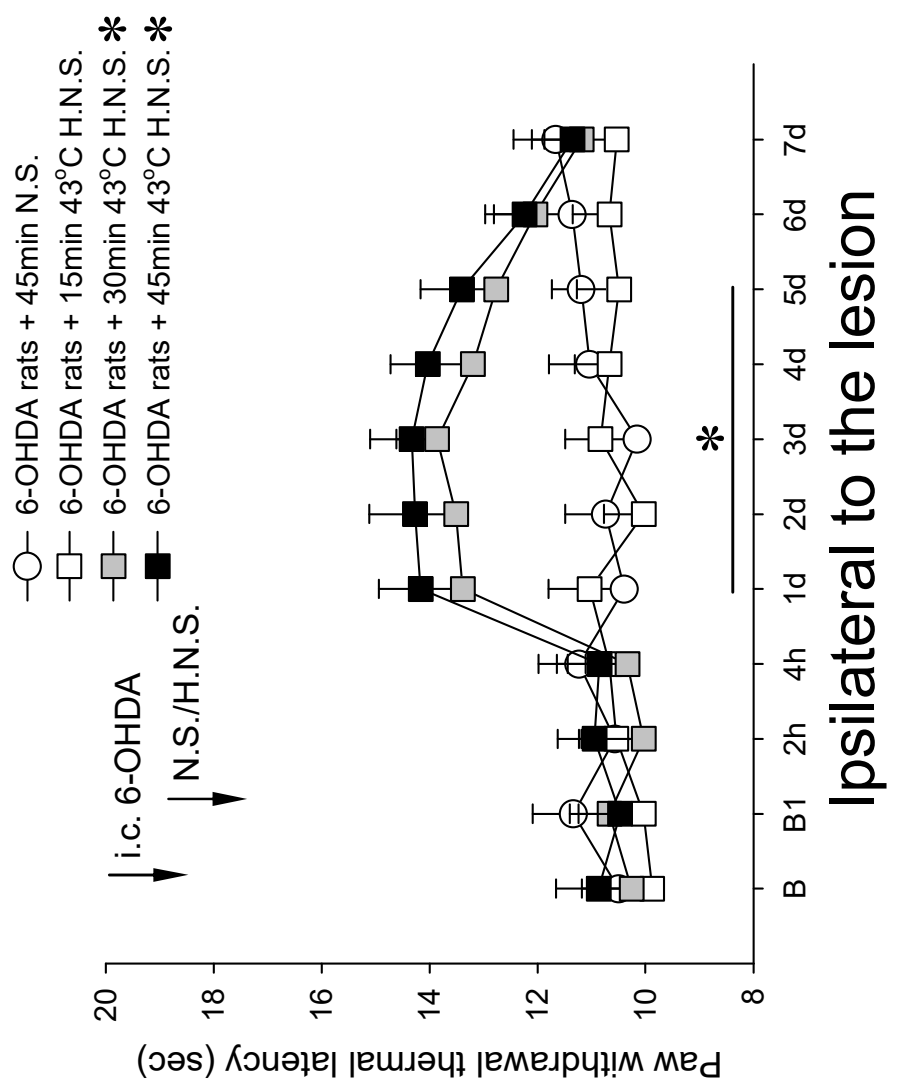




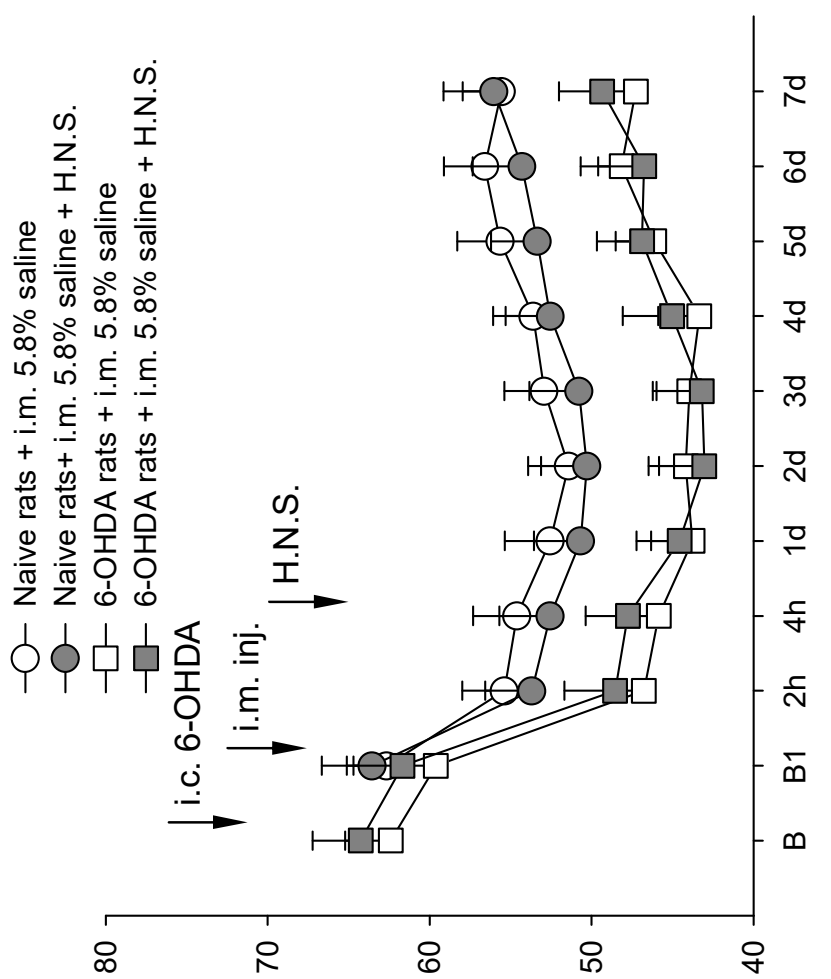

$m$

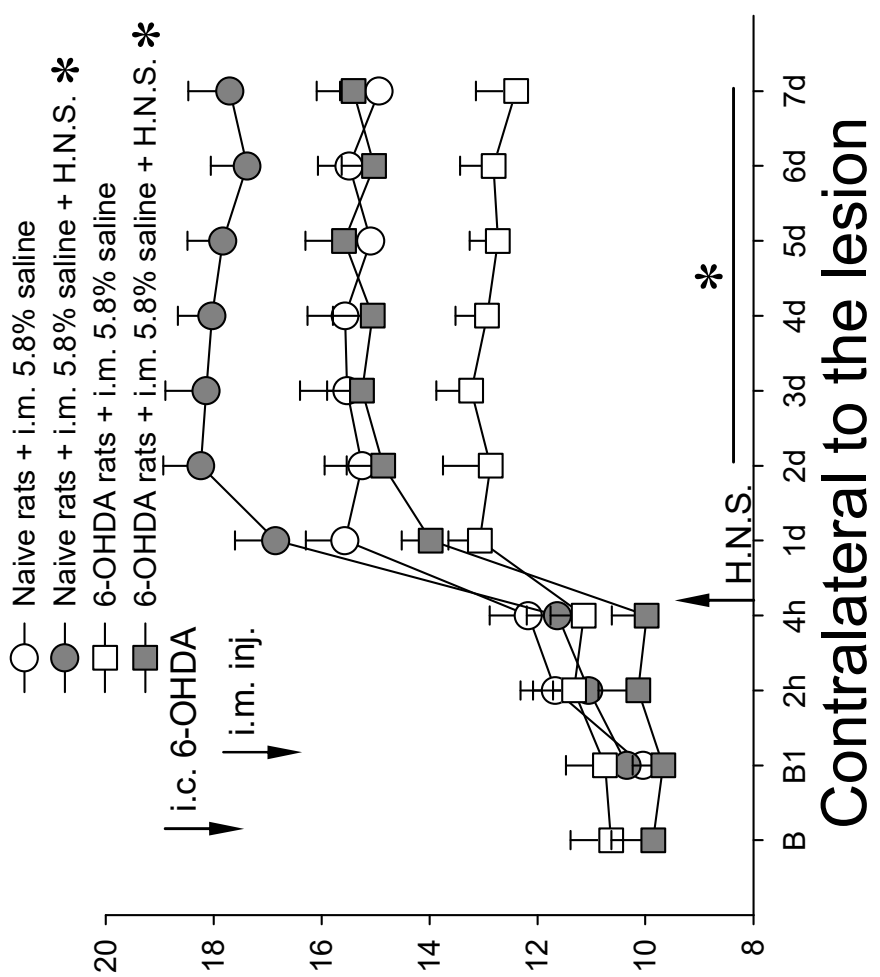

(эәs) Кэиәје| ןешәәц јемедрц!!м мед

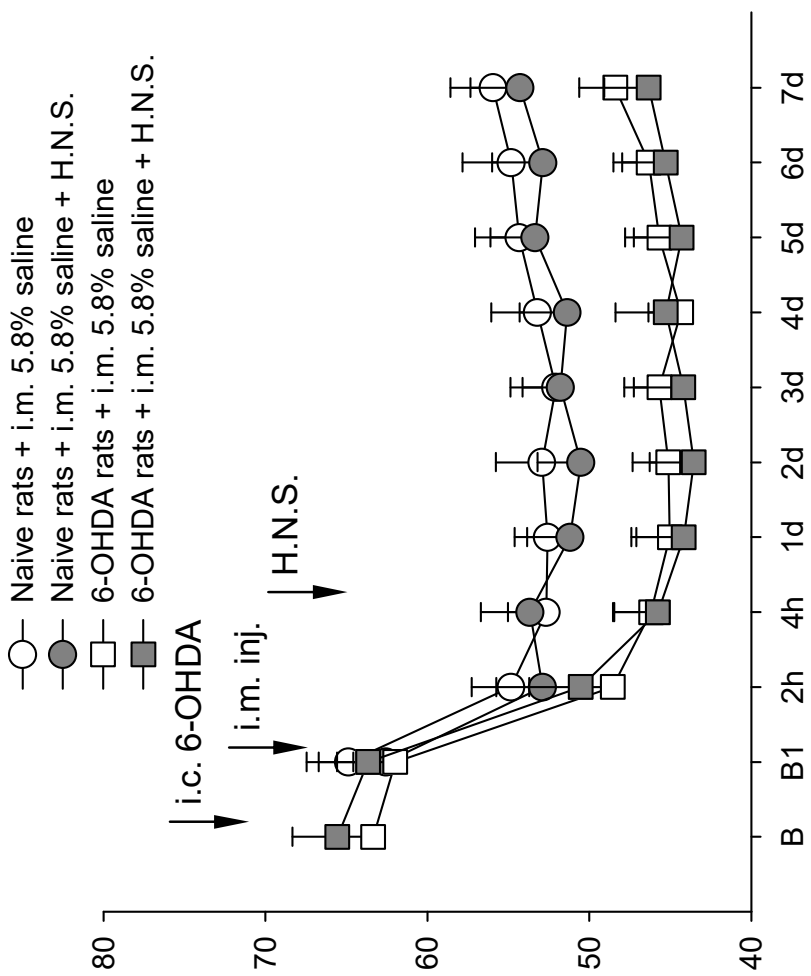

$\varangle \quad$ (6) ріочsәлчұ јео!иецәәш јемелрцұ!м мед

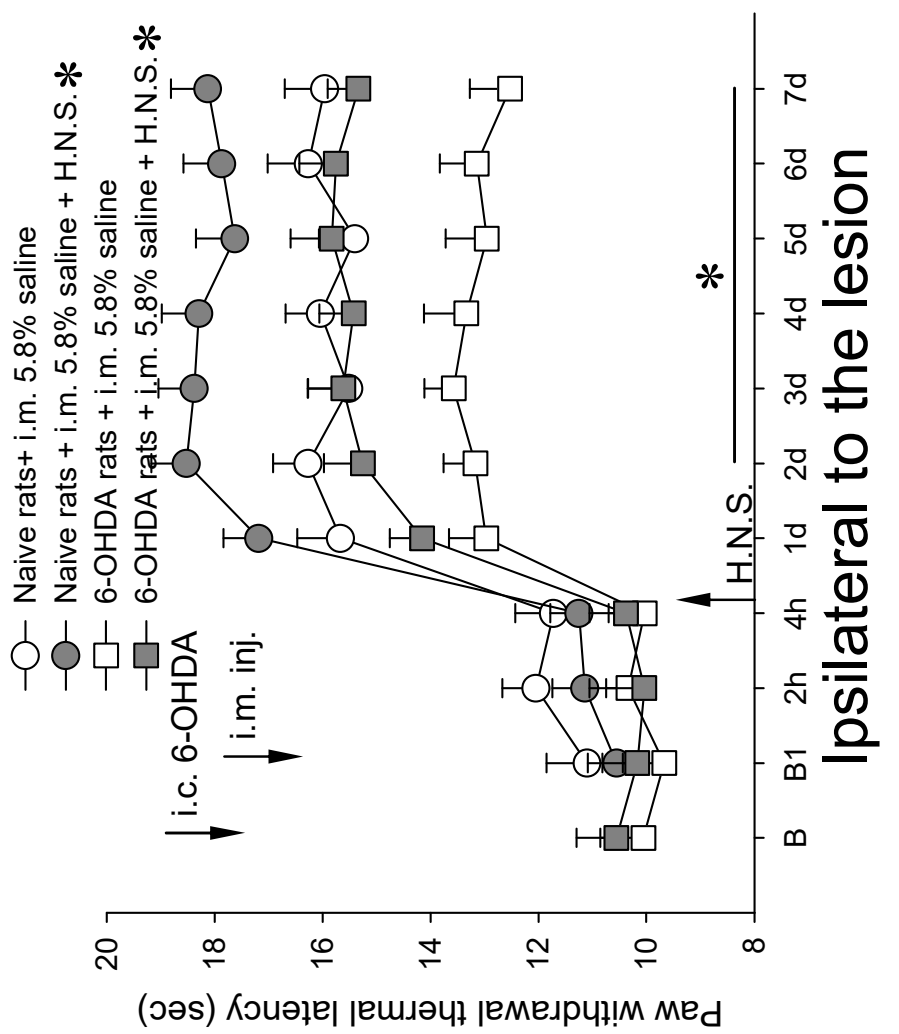



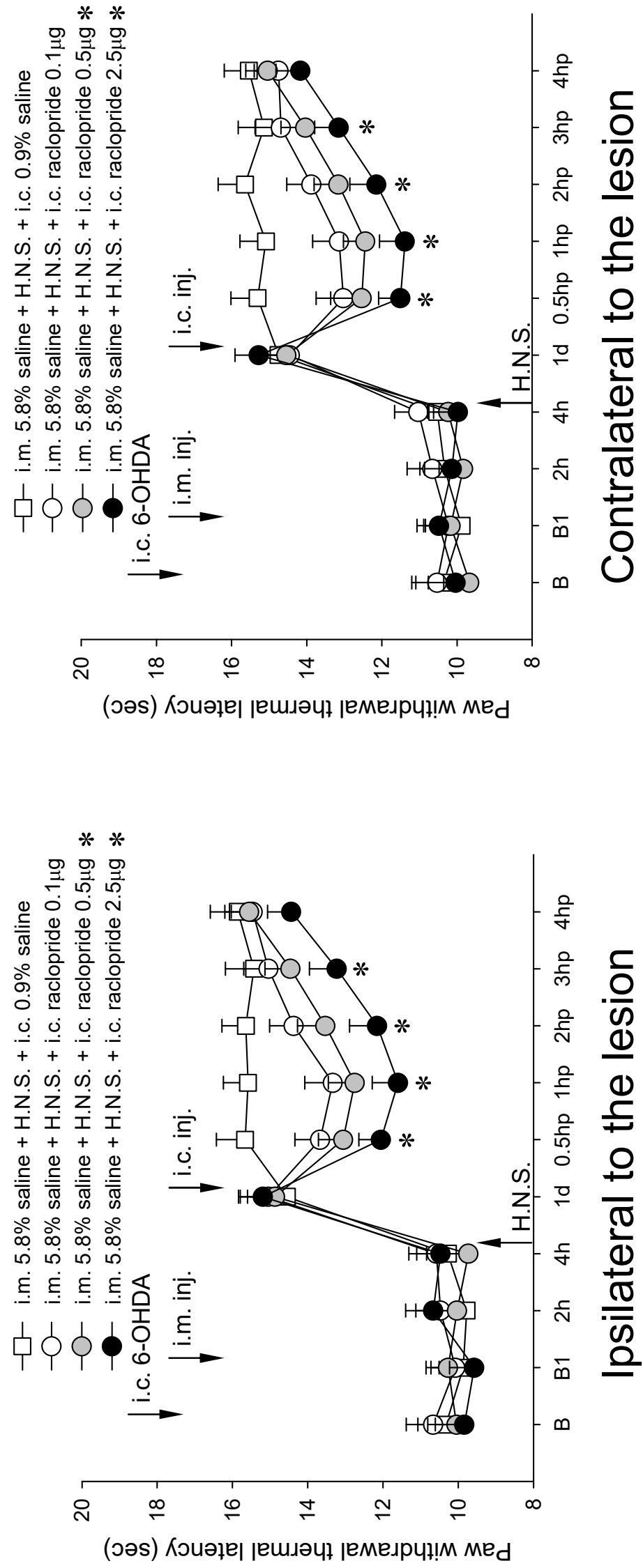

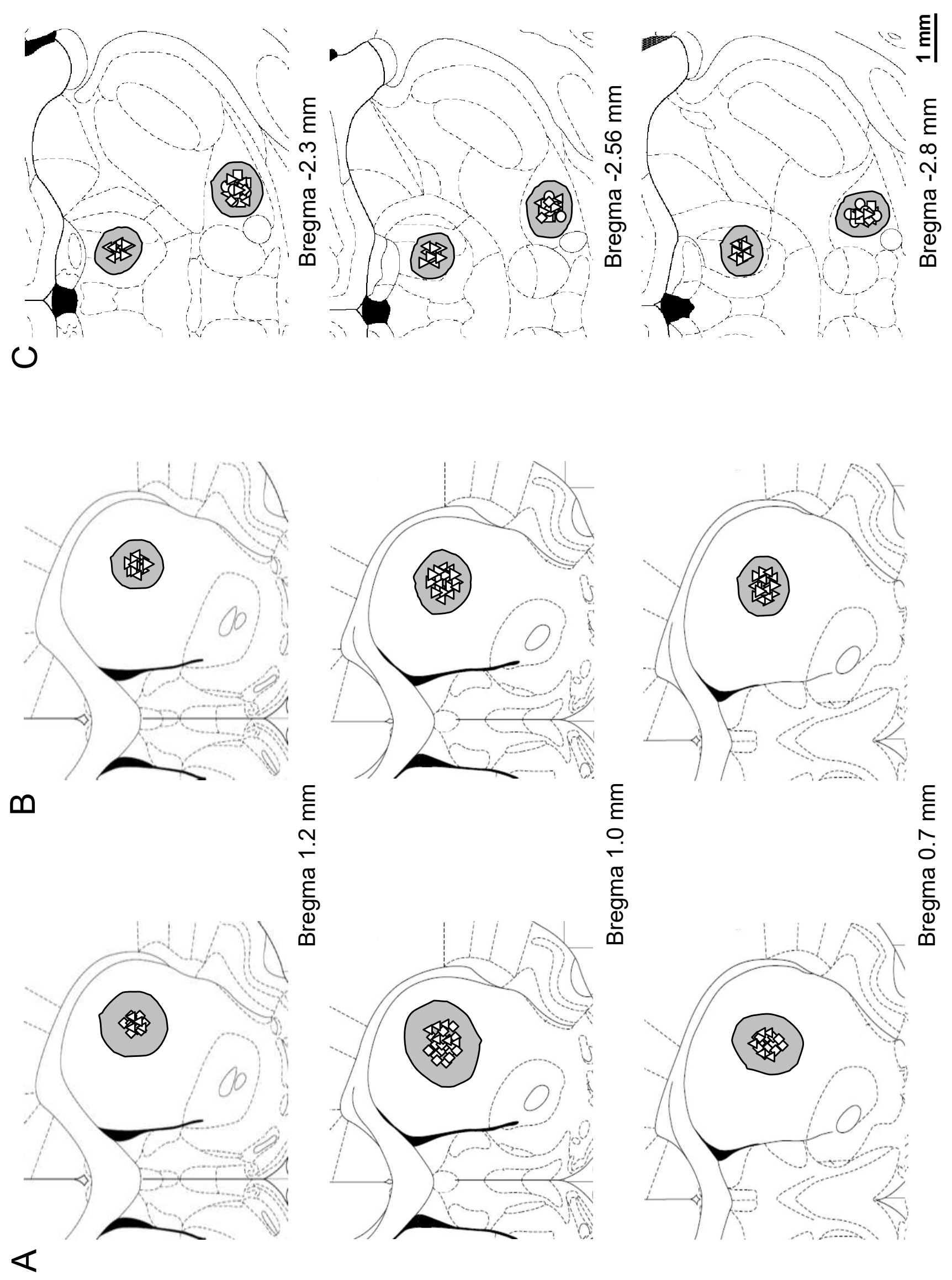


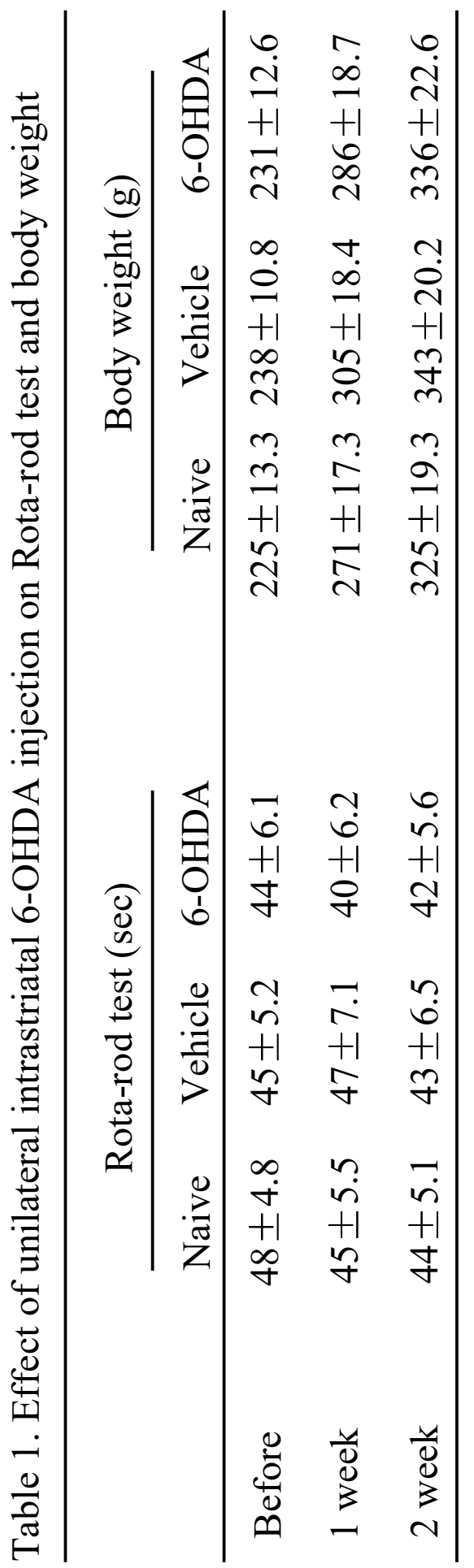

